Florida International University FIU Digital Commons

$11-13-2015$

\title{
Eyewitness Choosing Behavior: The Role of Ecphoric Experience and Non-Memorial Cues
}

Brian S. Cahill

Florida International University, bcahill@live.com

DOI: $10.25148 /$ etd.FIDC000163

Follow this and additional works at: https://digitalcommons.fiu.edu/etd

Part of the Cognitive Psychology Commons, Other Psychology Commons, and the Social Psychology Commons

\section{Recommended Citation}

Cahill, Brian S., "Eyewitness Choosing Behavior: The Role of Ecphoric Experience and Non-Memorial Cues" (2015). FIU Electronic Theses and Dissertations. 2269.

https://digitalcommons.fiu.edu/etd/2269

This work is brought to you for free and open access by the University Graduate School at FIU Digital Commons. It has been accepted for inclusion in FIU Electronic Theses and Dissertations by an authorized administrator of FIU Digital Commons. For more information, please contact dcc@fiu.edu. 


\section{FLORIDA INTERNATIONAL UNIVERSITY}

Miami, Florida

EYEWITNESS CHOOSING BEHAVIOR: THE ROLE OF ECPHORIC EXPERIENCE AND NON-MEMORIAL CUES

A dissertation submitted in partial fulfillment of the requirements for the degree of

DOCTOR OF PHILOSOPHY

in

PSYCHOLOGY

by

Brian S. Cahill 
To: Dean Michael R. Heithaus

College of Arts and Sciences

This dissertation, written by Brian S. Cahill, and entitled Eyewitness Choosing Behavior: The Role of Ecphoric Experience and Non-Memorial Cues, having been approved in respect to style and intellectual content, is referred to you for judgment.

We have read this dissertation and recommend that it be approved.

Stewart D'Alessio

Ronald P. Fisher

Nadja Schreiber Compo

Stephen D. Charman, Major Professor

Date of Defense: November 13, 2015

The dissertation of Brian S. Cahill is approved.

$\begin{array}{r}\hline \begin{array}{r}\text { Dean Michael R. Heithaus } \\ \text { College of Arts and Sciences }\end{array} \\ \hline \begin{array}{r}\text { Dean Lakshmi N. Reddi } \\ \text { University Graduate School }\end{array}\end{array}$

Florida International University, 2015 


\section{DEDICATION}

Earning a doctorate degree is by far the most difficult and rewarding experience of my young life. Although I had to pass my classes, develop my own research projects, write my own papers, pass my qualifying exams, and pass my dissertation defense on my own I could not have accomplished so much personally if it was not for some very special people in my life. While I am sure these people will be thankful and touched with my kind words here, even if no one other than us will likely ever read this again, I am not sure that I will ever be able to fully express to them how much they truly mean to me. At the very least I would like to dedicate my dissertation to these special people.

To my mother Mary Jo Cahill: You are the most wonderful woman I have ever known. Your uncanny ability to remain hopeful and strong regardless of the situation amazes me. Even after having multiple strokes you end up consoling us when it should be the other way around. Your undying generosity and support of your children is astounding! I was by no means an easy child to raise. Regardless of what the teachers told you and me, you always believed that I had the ability to do great things with my life. Because of this amazingly biased view only a loving mother could have of her child you supported me time and time again when no one else was willing to see my potential. Bottom line is I would not be here if it was not for your undying love and support Mom, so from the bottom of my heart and with tears in my eyes I thank you once again for loving me as only you can. I also want you to know that even if you cannot make it to my graduation because of these most recent strokes it is ok because you will be there in my heart as I take the stage on our special day. I love you Mom. 
To my sisters Noelle Saccoccio and Kristin Smith: What better sisters could a brother ask for? You are both funny, smart, loving, and undeniably supportive. To be sure, if it was not for both of you supporting me throughout this seemingly endless pursuit of degrees both emotionally and financially I would not be a doctor today. The fact that you both were willing to take care of our Mom while allowing me to pursue this dream of mine speaks volumes about the type of woman you both are. I can only hope that you feel the same way about me and that you know how much I appreciate your love and support. I want you both to know that I love you very much and that this accomplishment is yours as well. I cannot wait to hug you both as a doctor as we celebrate our special day together.

To my Uncle, Jim Emling: I wanted to thank you for showing me how a man should be. He should be loyal, honest, hardworking, and family oriented. I have never known a man who embodies these characteristics more so, and I am so proud to have you as my Uncle. Time and time again you helped me on this journey, and I just want you to know how much I appreciate it. I hope that I have made you proud to be my Uncle, and I love you very much!

To Steve Charman, my dissertation advisor: I am not sure how to express to you how much of an impact you have had on me both personally and professionally. The knowledge you have passed on to me is invaluable. I am a better researcher, thinker, and teacher because of you. Also, your patience and willingness to help your students is something you should be very proud of. Of the 7 years I have worked with you I cannot recall a time when I passed by to either get help from you or to just bounce ideas off of 
that you were not willing to help me. I will always cherish those last minute work days at your house finishing my dissertation edits over beer and some good Thai food! Although I will always be better dressed than you and have better taste in music, I will continue to learn from you and can only hope that one day I can become as good of a thinker and researcher as you! I love you man thanks!

To Fred Coolidge, my masters’ advisor: Fred, I am a doctor now! I cannot believe it. If it was not for you helping a gifted but unpolished enthusiastic kid become a competent writer and critical thinker I would not be here today. I will never forget the nights I spent listening to the Cellar Dwellers and taking advantage of your generous open drink policy! Or the night before my defense when I introduced you to the one and only Les Claypool for the first time. Even though we were born many years apart and began our relationship as an academic one, I soon realized that we were kindred spirits of different ages. From the bottom of my heart you will always be my academic father, and I love you very much!!!

To my research assistants Caroline Perez, Sara Oramas, and Jenny Youngblood: I have worked with well over 30 research assistants in my young career and I can honestly say you three are some of the best. Because of all of your hard work I am a doctor today! I especially want to thank Caroline for everything you have done for me. You will never know the amount of stress you saved me with all of your help, thank you so much!

To the love of my life Cindy Perez: I saved you for last because no one has helped me more than you my love. Every day for the past four years you have supported me in this pursuit. You have put your professional and personal life on hold for me to 
accomplish this goal and I cannot tell you how much that means to me and how much that speaks to the kind of woman you are. You were there by my side during my good days and more importantly during my bad days. You kept our house together and our babies, Pepper and Lebowski, at home happy when I was stressed beyond limits with my dissertation. Those nights when I slept in my office because I was working so many hours you were the one at home making sure everything was taken care of so when I did walk through the door I could relax. You always knew when I needed a laugh and/or a hug and never disappointed in either case. I cannot wait to begin this new chapter in our lives and I want you to know that this degree is as much mine as it is yours. I love you from the bottom of my heart and cannot wait to see your warming smile in the crowd while I walk across that stage. Just know that now it is your time to chase your dreams as I will be right there to support you as you have supported me, I love you my baby!!!!! 


\title{
ABSTRACT OF THE DISSERTATION
}

\section{EYEWITNESS CHOOSING BEHAVIOR: THE ROLE OF ECPHORIC EXPERIENCE AND NON-MEMORIAL CUES}

by

\author{
Brian S. Cahill
}

Florida International University, 2015

Miami, Florida

\section{Professor Stephen D. Charman, Major Professor}

Researchers' attempts at understanding the processes underlying witness choosing behavior have focused on applying models that predict that identifications will be primarily driven by memorial factors. However, research has shown that several nonmemorial variables affect witness choosing behavior (e.g., administrator influence, clothing bias, co-witness information); thus a full understanding of the processes underlying witness choosing behavior needs to account for these effects. While the memory-based models do attempt to provide explanations for the effects of nonmemorial based variables on choosing behavior they all do so within a memorial context. However, I will argue a lineup task is not simply a memory task but a task that allows both memorial and non-memorial variables to impact choosing behavior, with the latter affecting choosing through an inferential process.

The purpose of the present study was to provide an initial test of a novel, inferential based framework (i.e., the Competition/Corroboration Conceptualization). In short, this framework predicts that the effect of non-memorial cues on choosing behavior will occur via leading witnesses to deliberatively infer who the suspect is, and that the 
extent to which a deliberative process is engaged is dependent upon the witnesses' ecphoric experience.

Study $1(N=146)$ had mock-witnesses view several lineups with non-memorial cues embedded in them; results showed that mock-witnesses engaged in an inferential process by using the cues in the lineup to help guide their choosing behavior. Study 2 ( $N$ = 376) had witnesses view either a target-present or target-absent lineup where a nonmemorial cue suggested that witnesses should either identify the target, identify a specific filler, or was not included. Witnesses then made an identification decision. Results from study 2 showed that the presence of a non-memorial cue suggesting the suspect's guilt increased suspect identifications compared to its absence, and importantly, that this effect was greater for witnesses who had a weak ecphoric experience.

Findings across both studies suggest that an inferential based framework of witness choosing more fully encompasses the underlying nature of witnesses’ phenomenological experience. Practical implications and future directions are discussed. 


\section{TABLE OF CONTENTS}

CHAPTER

PAGE

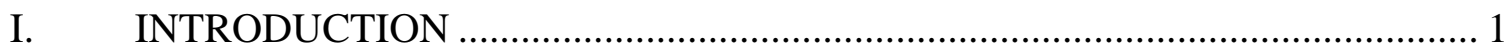

The Need for Theory................................................................................ 1

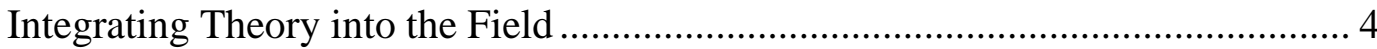

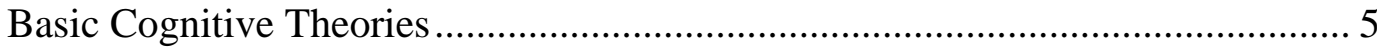

WITNESS Model of Eyewitness Choosing Behavior ......................................... 10

Motivation and Social Influence in a Lineup Task ........................................... 12

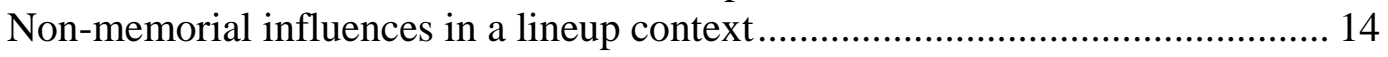

A Novel Model of Eyewitness Choosing Behavior ............................................ 19

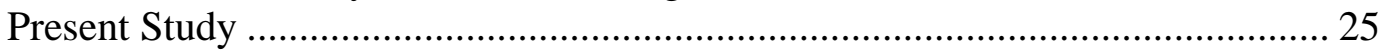

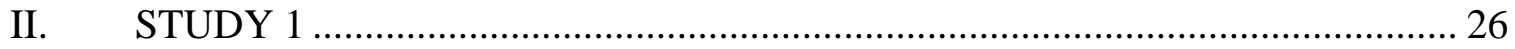

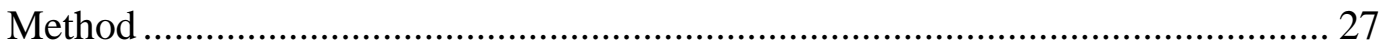

Participants and Design............................................................. 27

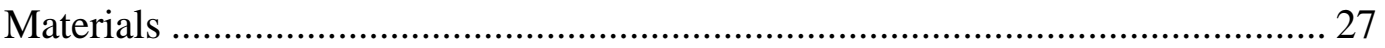

Non-memorial cue stimuli .................................................................. 27

Lineup construction .............................................................................. 28

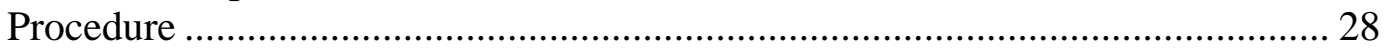

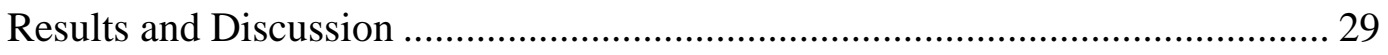

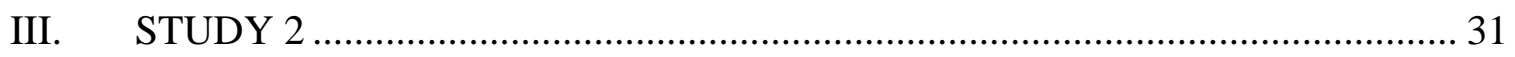

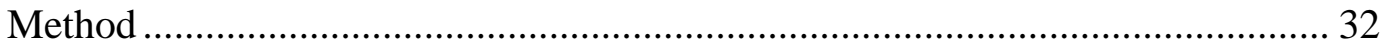

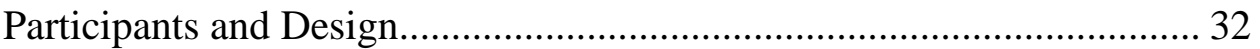

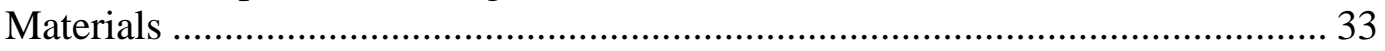

Mock crime video ....................................................................... 33

Lineup construction ....................................................................... 33

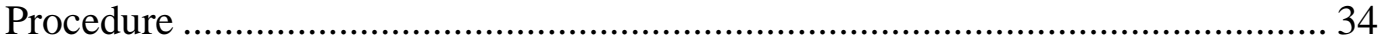

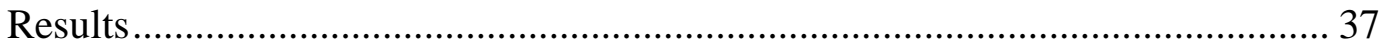

Manipulation Check.................................................................... 37

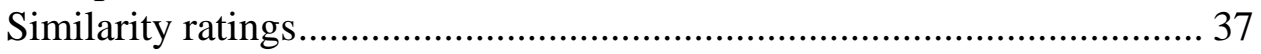

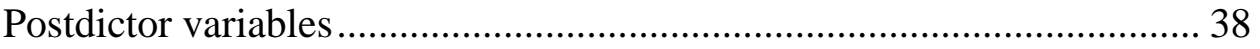

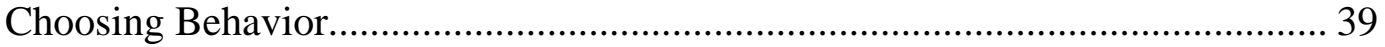

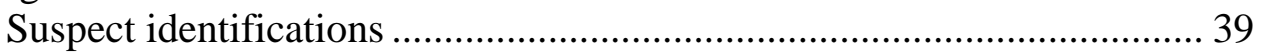

Filler identifications ................................................................... 42

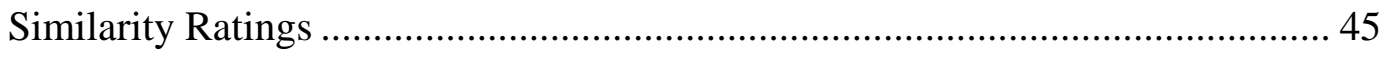

Target-present mediation model ...................................................... 45

Target-absent mediation model........................................................... 46

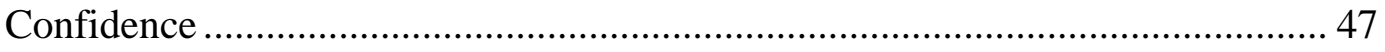

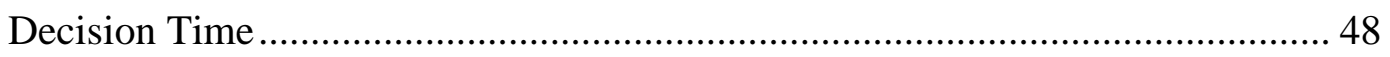

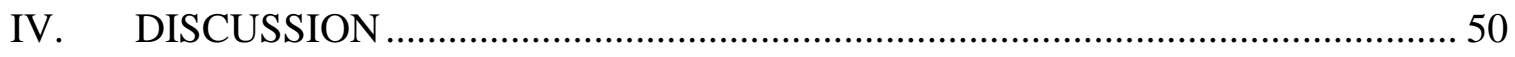

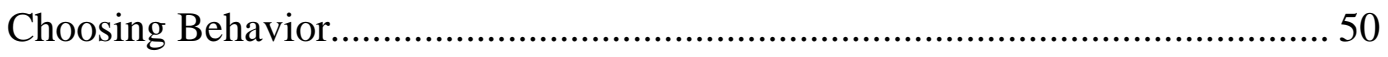

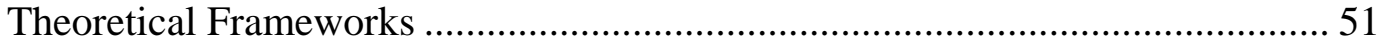


Criterion shift ............................................................................. 52

Reassessment of match values ............................................................. 53

Inferential based framework .................................................................. 54

Decision time and confidence ............................................................. 56

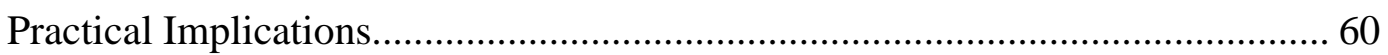

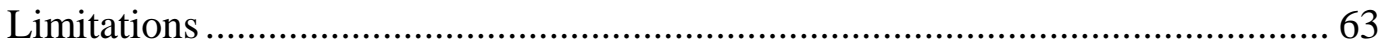

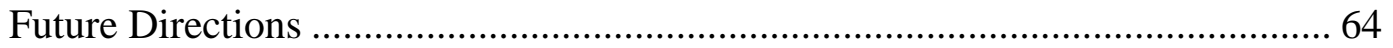

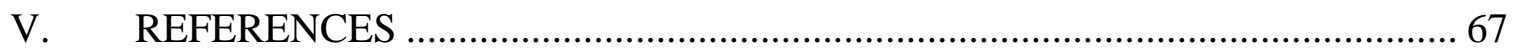

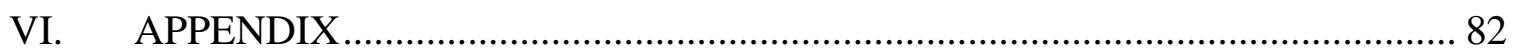

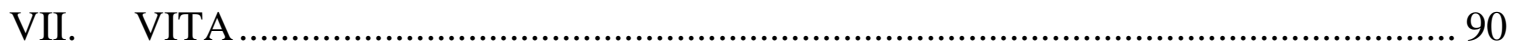




\section{LIST OF TABLES}

TABLE

PAGE

1 Probability and Odds of Identifying the Suspect by Non-memorial Cue and

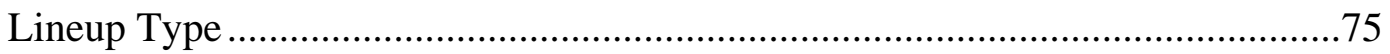

2 Probability and Odds of Making an Identification by Non-memorial Cue and Lineup Type................................................................................... 76

3 Probability and Odds of Identifying the Cued Filler by Non-memorial Cue and

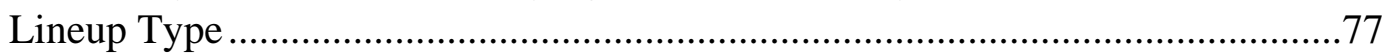

4 Means (SDs) of Witness Confidence Reports by Non-memorial Cue ..................78

5 Means (SDs) of Witness Decision time by Non-memorial Cue and Lineup

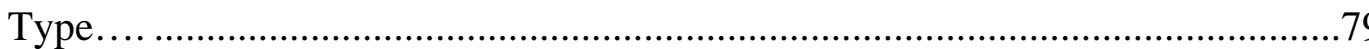




\section{INTRODUCTION}

In his seminal work, Hugo Münsterberg (1908) discussed many ways in which psychology and the law come in contact, be it through the detection of deception, false confessions, or, most relevant to this paper, eyewitness memory. Indeed, Münsterberg was one of the earliest proponents of applying psychological findings to solve real-world issues. And although he may be better known for his ideas regarding applied science, he also viewed theoretical understanding as an important goal within science (Münsterberg, 1899). Since its beginning with Münsterberg's work to contemporary times, the goal of eyewitness researchers has been to empirically evaluate the factors that affect eyewitness memory so we may positively contribute to the legal system. And after over 100 years of empirical interest researchers have amassed a large corpus of research on eyewitness memory and decision making and have made significant contributions to the legal system leading to many positive changes that will ultimately lead to improved outcomes. However, despite the many successes, the eyewitness identification field as a whole has made relatively little theoretical progress in understanding the processes that underlie performance (Lane \& Meissner, 2008).

\section{The Need for Theory}

If the field is flourishing with the current applied perspective why do we need to find a role for theory? The very phenomena that we study (i.e., eyewitness memory and decision making) are applied issues, and the goal of our research will always be to contribute our findings to the legal system. And although much of the success within the field is the result of directly tackling individual problems (e.g., lineup bias), there are 
reasons why it would be a fruitful endeavor to develop more theoretically oriented research programs to understand the identification process.

First, we will be better able to communicate our research findings to the legal community if we can provide theoretically driven explanations (Turtle, Read, Lindsay, \& Brimacombe, 2008). That is, the substantial time and monetary cost of implementing policy changes combined with the legal community’s depth of training in empirical methodology at times makes it difficult to effectively persuade the legal community to adopt certain policy changes. However, a strong theoretical framework that provides a deeper understanding of witness choosing behavior will allow researchers to better communicate the reasoning behind our policy recommendations, thereby, reducing the skepticism of policy makers. This is of utmost importance, given the very reason why we study eyewitness decision making is to help improve the legal system.

Second, one of the main criticisms of eyewitness memory research is that the results are not valid unless they mirror real-world conditions (Lane \& Meissner, 2008). An excellent example of this argument was provided by Clark (2008) in his one-legged, six-toed Scotsman example. An expert is testifying in a case and discusses the effect of certain variables on eyewitness accuracy. The witness in the case is a one-legged, sixtoed Scotsman and the prosecution argues that the results of the research are not relevant for this witness because no one-legged, six-toed Scotsman was a participant in the research. Research literature will never be able to approximate every conceivable combination of variables that will be present in real cases. However, theoretical development will allow researchers to apply findings to non-studied circumstances (Clark, 2008). 
Third, theoretically motivated research is much more likely to lead to greater progress in our understanding of the phenomenological experiences witnesses engage in while viewing a lineup compared to studying individual problems in a piecemeal fashion (Lane \& Meissner, 2008). Furthermore, greater understanding of the phenomenological experiences will have greater impacts on practical advancements (Brewer, Weber, \& Semmler, 2007). That is, to truly develop innovative, practical advancements that will lead to more diagnostic identifications we must first understand the phenomenological experiences that differentiate accurate from inaccurate witnesses. In sum, although our field has enjoyed much success thus far, theoretically motivated research is necessary to significantly advance our understanding of the phenomena we study and to develop the most impactful practical advances.

As noted by Brewer et al. (2007), an excellent illustration of how theoretically driven research possesses much power in providing the most impactful practical advances is the development of the sequential lineup procedure (Lindsay \& Wells, 1985). Few advancements within the eyewitness literature have enjoyed the level of impact that the development of the sequential lineup procedure has had. The development of this novel lineup procedure was driven by theoretical predictions regarding the nature of judgments in which witnesses engage while making an identification. Wells (1984) proposed two judgment strategies that eyewitnesses may engage in while viewing a lineup. That is, an eyewitness may compare the lineup members to each other and then choose the lineup member who looks most like the perpetrator (relative judgment). In comparison, an eyewitness may compare each lineup member to their memory of the perpetrator and choose the lineup member who best matches their memory of the perpetrator (absolute 
judgment). On the basis of the aforementioned judgment strategies, Lindsay and Wells (1985) developed a novel lineup procedure, the sequential lineup, to reduce eyewitnesses’ ability to use relative judgments and thereby forcing them to use absolute judgments. The procedure achieves this quite simply by having witnesses view photographs of lineup members sequentially (one at a time) and making a decision (yes or no) before moving on to a new photograph. The sequential lineup procedure contrasts the historically used lineup procedure in which all photographs of lineup members are presented simultaneously and eyewitnesses are allowed to look at all pictures before making an identification decision. Importantly, Lindsay and Wells reasoned that if eyewitnesses were forced to look at the photographs in a sequential fashion they would not be able to engage in a relative judgment strategy. Since the Lindsay and Wells study, much research has shown that sequential lineups, compared to simultaneous lineups, consistently produce a greater reduction in false identifications from target-absent lineups compared to the decreased rate of correct identifications from target-present lineups (for an overview see Steblay, Dysart, Fulero, \& Lindsay, 2001; for an alternative view, however, see Carlson, Gronlund, \& Clark, 2008; McQuiston-Surrett, Malpass, \& Tredoux, 2006). In sum, this example clearly illustrates theoretically motivated research is very effective, not only in generating research that will ultimately lead to a greater understanding of the phenomenological experiences witnesses engage in while viewing a lineup, but also in generating those practical advances that will contribute most to the legal system.

\section{Integrating Theory into the Field}

At the most basic level eyewitness researchers are ultimately interested in understanding why some witnesses make a lineup choice and others do not. Therefore, to 
integrate theory into the eyewitness field with any hope of success, theory must be able to explain the choosing behavior of eyewitnesses (Brewer et al., 2007). Specifically, theory must be able to account for two fundamental problems: 1) mistaken identifications of an innocent suspect and 2) failing to identify the perpetrator when they are present in the lineup. It is clear that the ultimate goal of eyewitness researchers is to 1) stop witnesses from choosing when the perpetrator is not in the lineup and 2) ensure that witnesses choose the perpetrator when he/she is in the lineup (Brewer et al., 2007). It seems there exist two routes for researchers to develop/integrate theory into the field to help explain the choosing behavior of eyewitnesses. One is to apply well developed theories from other, related, areas of psychology (e.g., dual-process recognition theories) to examine their ability to account for choosing behavior. Alternatively, a second route is to develop theories within the field to examine their ability to account for choosing behavior. Following will be a discussion of the theories researchers have used to explain witnesses' choosing behavior.

\section{Basic Cognitive Theories}

The lineup task eyewitnesses complete is, quite simply, a recognition task. Indeed, in a recognition task people are typically provided with choice options (in the case of a lineup witnesses are given photographs) and are tasked with identifying an item as being one they have been exposed to previously or not (in the case of a target-present lineup, the perpetrator of the crime). Despite some differences between a lineup task and a recognition task (e.g., many recognition tasks entail a single-item response task, whereas lineups are a multiple-item response task), lineup tasks are essentially a test of 
one's recognition memory. Thus, applying theories generated by recognition memory researchers to a lineup situation seems appropriate.

To date there exist several memory models (known as dual process models) that propose recognition memory judgments are the result of two distinct memory processes: recollection and familiarity (for a review see Yonelinas, 2002). Though there are several dual-process memory models, the core assumptions of these models are quite similar. Recollection based judgments are typically thought to reflect an effortful, deliberative process where retrieval of specific information about a study event occurs, whereas familiarity based judgments are typically thought to reflect a non-effortful, automatic process where a feeling of familiarity occurs (Atkinson, Hertmann, \& Wescourt, 1974; Jacoby, 1991; Yonelinas, 1994). For instance, imagine you are walking on campus and you see someone you recognize and you also remember where you recognize them from; this would be indicative of a recollection based judgment. On the other hand, if you recognize them but you cannot remember from where, this would be indicative of a familiarity based judgment. There is also general agreement that familiarity is faster than recollection (Atkinson, Hertmann, \& Wescourt, 1974; Jacoby, 1991; Yonelinas, 1994) and the two processes function independently at the time of retrieval (Jacoby, 1991; Tulving, 1982; Yonelinas, 1994).

To evaluate the theoretical claims of these various dual-process models researchers have developed several measurement techniques to assess these two processes (e.g., process-dissociation procedure, receiver-operating-characteristic procedures, the remember/know procedure). One of the commonly used techniques to assess the contribution of the different types of memory (i.e., recollection, familiarity) to 
the overall memory performance on a recognition task is the remember/know procedure (RK; Tulving, 1985). In the remember/know technique participants are required to introspect about the basis of their memory judgments and to indicate whether a given item was "remembered” (R) or "known” (K). Specifically, if recognition was accompanied by the recall of contextual details (e.g., the color of the stimulus), a (R) response should be made, indicating a recollective experience; however, if recognition was not accompanied by the recall of any contextual details, a (K) response should be made, indicating a familiarity experience (Tulving, 1985). Importantly, the results obtained using the RK procedure reveal similar patterns as those found using other techniques to measure the contribution of the different types of memory (i.e., recollection, familiarity) to the overall memory performance, such as process-dissociation and receiver-operating-characteristic procedures (Yonelinas, 2001; Yonelinas, Kroll, Dobbins, Lazzara, \& Knight, 1998). That is, recognition memory judgments accompanied by R judgments, although slower in nature, are more accurate and made with greater confidence, than those accompanied by K judgments (Yonelinas, 2002).

Given the robustness of these findings and the parallel between a recognition task and a lineup task, it seems plausible to expect a similar pattern of results to be revealed in identification decisions. To date, several researchers have successfully used dual-process models to account for witness choosing patterns (Meissner, Tredoux, Parker, \& MacLin, 2005; Palmer, Brewer, McKinnon, \& Weber, 2010). For example, researchers have demonstrated accurate identifications were more likely to be accompanied by $\mathrm{R}$ judgments, which parallels the findings within the cognitive literature (Palmer et al., 2010). 
Another approach used to account for eyewitness choosing behavior is Signal Detection Theory (SDT; Green \& Swets, 1966). According to SDT, people’s ability to distinguish new from old stimuli is a function of two independent parameters calculated mathematically. One of the parameters is called discriminability which is an individual's ability to correctly detect a signal (in a lineup this would be correctly identifying the perpetrator) vs correctly rejecting its absence (in a lineup this would be correctly rejecting a lineup that did not contain the perpetrator). Factors that affect the quality of memory (e.g., encoding time, attention, encoding conditions, etc.) influence an individual's discriminability, with greater discriminability resulting from a higher quality memory. The second parameter is called response criterion, which refers to the amount of evidence needed for an individual to respond that a signal has been detected. Response criterion is influenced by social and/or instructional factors that bias an individual to respond either conservatively or liberally depending upon the social and/or instructional factor presented. Given that a lineup task is essentially an old/new recognition task the application of this theory to understanding eyewitness choosing behavior is appropriate and as will be discussed below has been fruitful.

Historically, the standard lineup presentation procedure used in the legal system consisted of showing a witness a set of photographs simultaneously that contained one suspect, with the remaining photographs consisting of "known innocent” persons (a simultaneous lineup). While debate still exists regarding the appropriateness of the simultaneous lineup procedure (see Gronlund, Wixted, \& Mickes, 2014; Wells, Smith, \& Smalarz, in press), many researchers would recommend the use of an alternative lineup presentation procedure (i.e., a sequential lineup). The sequential lineup procedure, 
originally introduced by Lindsay and Wells (1985), consists of sequentially showing a witness a set of photographs that contained one suspect, with the remaining photographs consisting of "known innocent" persons ${ }^{1}$. Decades of research, including several metaanalyses (for example, Steblay, Dysart, Fulero, \& Lindsay, 2001; Steblay, Dysart, \& Wells, 2011) contrasting these two lineup presentation procedures has revealed the sequential lineup presentation yields a greater reduction in false identifications than in correct identifications (with this pattern commonly referred to as the sequential superiority effect). Furthermore, and arguably more importantly, the sequential lineup procedure is more diagnostic of guilt compared to the simultaneous lineup procedure (Steblay et al., 2011).

Generally, two explanations have been proposed to account for the dissociated choosing patterns between simultaneous and sequential procedures. First, some researchers have argued the increase in choosing rates found in simultaneous lineups is the result of the type of judgment in which witnesses engage. Specifically, the simultaneous procedure leads witnesses to engage in a strategy that leads to more choosing (i.e., relative judgment strategy), while the sequential procedure, by nature, removes this context thereby leading witnesses to use a strategy that leads to less choosing (i.e., absolute judgment strategy; Lindsay \& Wells, 1985). Second, others have explained the dissociated choosing patterns within a recognition framework. Specifically, the sequential procedure may result in an upward shift of a participants' decision criterion (i.e., the amount of evidence required to make an identification); in other words, sequential lineup presentation may simply make witnesses less likely to choose overall (Ebbesen \& Flowe, 2002). To evaluate the criterion shift explanation researchers 
developed a novel lineup recognition paradigm which provided the necessary responses needed to measure participants' decision criterion; across three studies they found support for the decision criterion shift explanation (Meissner et al., 2005). Specifically, they found that participants shown a sequential lineup responded more conservatively (i.e., they were less likely to choose) compared to those shown a simultaneous lineup. Thus, SDT has provided a theoretical account of the dissociation of choosing patterns found between simultaneous and sequential lineups. Thus far, we have focused solely on the application of basic recognition models to account for eyewitness choosing behavior. Next, a model that was designed specifically to account for eyewitness choosing behavior will be discussed (i.e., the WITNESS model).

\section{WITNESS Model of Eyewitness Choosing Behavior}

Although many researchers initially attempted to account for witness choosing behavior using dual-process recognition models, some have attempted to develop areaspecific models. Clark (2003) developed a mathematical model called WITNESS which has successfully accounted for witness choosing behavior. As previously mentioned, much research suggests witnesses engage in either a relative or absolute judgment strategy (or some combination of both) to make an identification decision. With this theoretical framework in mind, the model assumes witnesses make lineup decisions by matching each lineup alternative to their memory of the culprit; the decision whether to make an identification or not is then determined by a weighted combination of relative and absolute match information. Specifically, match values associated with the lineup members (roughly, their similarity to the witness's memory of the criminal) are calculated by a witness and then these match values are applied to a decision rule (i.e., 
the witness's decision criterion). For each lineup member the witness will match various features of a lineup member (e.g., facial structure, hair and eye color, facial hair, height, etc.) to their memory of those features possessed by the perpetrator and then weight the importance of each feature in determining the level of match between the lineup member and their memory of the perpetrator. For example, a witness using a decision rule based on a $100 \%$ weighting of absolute judgment match information will identify the lineup member who is the best match to the memory of the perpetrator if that lineup member's match value exceeds the witness's decision criterion. Alternatively, a witness using a decision rule based on a $100 \%$ weighting of relative judgment information will identify a lineup member if the difference between the lineup member with the highest match value and the lineup member with the next highest match value exceeds the witness's decision criterion. Importantly, the best match may be the result of either an absolute judgment (e.g., the best match is identified because they are a very good match to memory) or a relative judgment (e.g., the best match is identified because they are a much better match than anyone else in the lineup) or some combination thereof. Although there is less research evaluating the effectiveness of the WITNESS model in accounting for eyewitness choosing behavior compared to the aforementioned dual-process recognition models it nonetheless has been shown to reliably account for a variety of eyewitness choosing patterns (Clare \& Lewandowsky, 2004; Clark, 2003; Clark, Marshall, \& Rosenthal, 2009; Goodsell, Gronlund, \& Scott, 2010).

Thus far I have discussed three theoretical approaches that have proven fruitful in accounting for various patterns of eyewitness choosing behavior. As a result these approaches have given researchers insights into the decision-making processes witnesses 
engage in while making a lineup decision. Although the aforementioned approaches differ in some respects, they share an underlying theme from which their predictions of eyewitness choosing behavior stem. Namely, a lineup task is predominately a memory task, and thus, an eyewitnesses' decision to choose or not choose a lineup member can be accounted for by the amount of match (or lack thereof) a lineup member has to the eyewitnesses' memory of the perpetrator and that witness's decision criterion. In other words, these approaches, for the most part, would predict non-memorial based variables would have little to no effect on choosing behavior, except insofar as they either (a) affect the witness's decision criterion, or (b) result in a re-assessment of the lineup members' similarity to the perpetrator. However, I will argue a lineup task is not simply a memory task, but is rather a memory task that occurs within a social context that allows nonmemorial variables to impact choosing behavior through an inferential process that cannot be accounted for with a decision criterion shift or a re-assessment of the lineup members' similarity to the perpetrator. This is not to say that memory is not the driving force underlying the phenomenological experience of the eyewitnesses' decision making. Rather, because of the nature of a lineup task, witnesses are inherently motivated to make an identification, leading them to look for non-memorial cues in an attempt to determine who the perpetrator is. Thus, it is important to develop and test theoretical approaches that are able to take into account these non-memorial variables and their effect on eyewitnesses’ decision making.

\section{Motivation and Social Influence in a Lineup Task}

The eyewitness and/or victim, the police, and the prosecutor are all motivated, albeit to varying degrees, to obtain a positive identification of the suspect. An 
eyewitness's and/or victim's motivation to make a positive identification of the suspect may stem from their wanting to feel good about their memory, that they are a good member of society because they helped the police, and, in the victim eyewitness case they can feel a sense of closure/justice. Furthermore, the police and prosecutors may be motivated to selectively seek out information that confirms their pre-existing hypotheses (i.g., confirmation bias; Kassin, Dror, \& Kukucka, 2013) to prove they are competent within their profession and/or to obtain justice for the victim.

This is not to say the motivation of the aforementioned parties is to simply get an identification of a suspect, regardless of guilt. However, in a criminal investigation, if an eyewitness is being shown a lineup it is because there is some suspicion on behalf of the investigators that the suspect is the perpetrator. This makes sense from both the witnesses' and an investigator's perspective. Witnesses may assume that if the police ask them to look at a lineup it is implied the police have a suspect; why else would they be asked to look at a lineup? Indeed, Memon, Gabbert, and Hope (2004) showed that over 90\% of participants across several identification experiments reported they assumed the perpetrator was in the lineup despite being provided with unbiased instructions. This assumption should result in witnesses being motivated to make a lineup identification. In sum, because of the specific nature of a lineup task the parties involved are all likely motivated, to some extent, to obtain an identification of the suspect.

The argument that a lineup task is more than simply an amotivational memory task, but rather is one that involves motivated witnesses, is not new (e.g., Wells \& Luus, 1990). Recently, there have been calls for the development of new lineup procedures (Brewer \& Wells, 2011) and the development of theoretical frameworks that take into 
account the influence of social variables on choosing behavior (Brewer et al., 2007;

Charman \& Wells, 2007a). The proposed studies are designed to test a theoretical account of witness choosing behavior that incorporates a non-memorial based inferential process into witnesses’ identification decisions.

\section{Non-memorial influences in a lineup context}

Multiple findings within the eyewitness area suggest that witnesses’ decisions are partly based on motivational - as opposed to strictly memorial - factors. Wells and Luus (1990) drew an analogy between a methodologically sound experiment and a lineup task. That is, like participants in an experiment, eyewitnesses' behavior during a lineup task may be guided by experimenter bias and/or demand characteristics if preventative steps are not taken (e.g., the use of a double-blind procedure). A large body of research shows experimenters may communicate either directly or indirectly their expectations to participants through their interaction with participants, termed Experimenter Expectancy Effects, and as such participants will allow these expectations to influence their behavior (Rosenthal, 1966).

Furthermore, when participants (or eyewitnesses) have preconceived ideas of the desired outcome, this awareness may affect their behavior during the experiment (or lineup task). These demand characteristics are likely to be present during a lineup task, given eyewitnesses’ expectation that the perpetrator is in the lineup. Again, much research has found evidence of the effect demand characteristics have on participant's behavior (Rosenthal \& Rosnow, 1991).

This analogy prompted Wells and Luus (1990) to propose a set of recommendations for conducting a lineup. For instance, to reduce the effect of 
experimenter bias, they suggested that lineups should be administered by someone who is blind as to who the suspect in the lineup is (i.e., double-blind procedure). As expected, findings within the eyewitness literature support the need for the use of a double-blind procedure. Specifically, results across multiple studies indicate that witness are more likely to choose from a lineup when the administrator had more contact with the eyewitness (Haw \& Fisher, 2004) or when the administrator was not blind (Greathouse \& Kovera, 2009; Phillips, McAuliff, Kovera, \& Cutler, 1999; Rhead, Rodriguez, Korobeynikov, Yip, \& Kovera, 2015). Also, witnesses - especially those with weaker memories - appear to look for indications from the lineup administrator as to the identity of the suspect in the lineup when they are motivated to make an identification (Greathouse \& Kovera, 2009). These findings suggest that witnesses' decisions are partly being driven by non-memorial factors and importantly that the extent to which the nonmemorial factors affect choosing behavior is dependent upon witnesses' ecphoric experience (i.e., the perceived sense of similarity between a stimulus and a person's memory (Tulving, 1981).

Another example of social influence on eyewitness choosing behavior is that of criminal face bias (Flowe \& Humphries, 2011; McQuiston \& Malpass, 2002), which is the tendency of eyewitnesses to select the most criminal-looking person from a lineup. Recently, Flowe and Humphries (2011) demonstrated this effect using a randomly obtained sample of real police lineups. Results showed that participants who did not receive a description of the suspect were biased toward choosing the most criminallooking faces. Furthermore, when asked to justify their lineup choices participants indicated they chose the person because they looked like a criminal. Perhaps most 
interestingly, this bias had more of an effect on participants who had no other information available to them. This finding provides some initial support that is directly relevant to the current paper. First, as with administrator influence, it shows that eyewitnesses' choosing behavior is affected by non-memorial cues. And, second, it provides a foundation that the effect of these non-memorial cues may be moderated by the ecphoric experience of the eyewitness.

Research investigating eyewitness confidence also provides evidence supporting the idea that (1) social influences do impact witnesses' decision making, and (2) these influences are moderated by the ecphoric experience of the eyewitness. A reliable finding within the literature is that confirming post-identification feedback from the administrator (i.e., “Good you identified the suspect”) inflates witnesses’ retrospective confidence in their identification decision (Wells \& Bradfield, 1998; see meta-analysis by Steblay, Wells, \& Douglass, 2014). Furthermore, research has shown that the confirming feedback effect is stronger for witnesses who are inaccurate (Bradfield, Wells, \& Olson, 2002; Charman \& Wells, 2012). Thus, these findings support the idea that witnesses do use non-memorial cues to guide them in their decision-making, and importantly, the effect of these non-memorial cues is greater when witnesses have a weak ecphoric experience compared to a strong ecphoric experience.

Thus far, I have established several important points. First, there exists a strong motivational component in a lineup task. Second, this motivation and the presence of social influence leads eyewitnesses to not simply rely on the memorial processes alone while making an identification decision but also non-memorial cues that are present in the lineup. Third, the effect of these non-memorial cues on choosing behavior may be 
moderated by the ecphoric experience of the eyewitness. An important question remains: Can the existing theoretical frameworks account for these data?

Again, the three theoretical frameworks (dual-recognition models, SDT, and the WITNESS model) that have been used to account for choosing behavior thus far are based on the idea that a lineup task is predominately a memory task; these approaches postulate that the effect of witnesses' motivation and/or non-memorial cues on choosing behavior would be changing their decision criterion (i.e., the amount of memorial match needed to make an identification). According to the criterion shift explanation the presence of a non-memorial cue should result in a specific pattern of data, that is, it should lower a witness's decision criterion thereby increasing choosing rates independent of the witness's ecphoric experience.

However, Clark et al. (2009) showed a different pattern of data inconsistent with a criterion shift explanation. They were investigating the effect of administrator influence on eyewitness identification decisions. The two influence conditions consisted of either providing cautionary statements (e.g., "take your time”; subtle-influence condition) or asked the witness directly to consider the most-similar lineup member (similarityinfluence condition). Interestingly, they found that witnesses in the subtle-influence condition were more likely to choose, but only for witnesses who viewed target-absent lineups, resulting in increased false identifications but not increased correct identifications. And most important to the current point, the subtle influence manipulation changed the distribution of choices in the target-absent condition. This latter pattern of data cannot be accounted for by the criterion shift explanation. For example, imagine a lineup in which lineup member 5 is the best memorial match. 
Decreasing a witness's decision criterion should certainly result in a higher identification rate; however, the overall distribution of choices would be the same. That is, because lineup member 5 is the best memorial match he would be picked at a higher rate compared to the other lineup members regardless of the witness's decision criterion. The effects of a manipulation that changes not only the overall choosing rate, but also the distribution of choices, cannot be explained via a simple change in decision criterion. As stated by Clark et al. (2009), changing the decision criterion can determine whether the best memorial match will be selected, but it cannot determine who the best match is.

Other data are also inconsistent with the criterion shift explanation. A criterion shift explanation predicts that a lowering of witnesses' decision criteria will result in increased choosing in both target-present and target-absent lineups; however, numerous findings have failed to produce this pattern of results. For instance, although most studies investigating the effect of biased/unbiased instructions show increases in both correct and false identification rates, some have only shown an increase in false identifications (e.g., Cutler \& Penrod, 1988; Cutler, Penrod, \& Martens, 1987; Malpass \& Devine, 1981). Also, a similar pattern has been shown when eyewitnesses are given instructions regarding the possible appearance change of the suspect (Charman \& Wells, 2007b).

Clearly, there exists data that the criterion shift explanation has a difficult time accounting for, but what about the WITNESS model? To account for his data that subtleinfluence changed the distribution of choices, Clark et al. (2009) proposed that instead of the match values being an unchanging static variable witnesses will update the match values when a non-memorial cue is present. The reassessment of match values explanation predicts the presence of a non-memorial cue may lead witnesses to re-weight 
the importance of certain features which would either lower (or raise) lineup members' match values, and importantly, change which lineup member is now the best match. To date, this modification to the WITNESS model has not been empirically tested.

\section{A Novel Model of Eyewitness Choosing Behavior}

Charman and Wells (2007a) proposed a model developed specifically to account for eyewitness choosing behavior. Their model, the Competition/Corroboration Conceptualization (CCC), is based in part from Logan’s (1988) instance theory. In brief, instance theory attempts to account for the development of automatic processes of any given stimulus. According to the theory, when first presented with a stimulus one begins by slowly responding in a deliberative algorithmic way to the stimulus, but with increased exposure to the stimulus one accumulates memories, or instances, of interacting with the stimulus. As such, at a certain point one stops responding to the stimulus using slow, deliberative algorithmic responses and instead responds to the stimulus based off of an accumulation of instances regarding responses to the stimulus. Importantly, deliberate and automatic processes do not operate in isolation but rather operate in parallel fashion, with the two processes racing and the one that finishes the race first controlling the outcome. Accordingly, as instances of the stimulus accumulate over time the response is more likely to be driven by memory-based processes than by the algorithmic-based processes. Of note, for the purpose of CCC, algorithmic- and memory-based responses are analogous to inferential and ecphoric processes, respectively.

On the basis of this framework, the CCC states that witnesses will have an ecphoric experience (i.e., recognition) and will also engage in inferential (i.e., reasoning) processes when looking at a lineup, and that there exists a trade-off between the two. For 
example, imagine a situation in which you were sitting next to a man at the bus stop for 30 minutes and then gets up and robs a young woman who was approaching the bus stop. If the police showed you a lineup containing a picture of this individual taken soon after the crime and five fillers you would likely immediately recognize the perpetrator and correctly identify him. Because your memory was strong and a recent picture was included in the lineup you were likely to have had a strong ecphoric experience and therefore would not have to try and reason (i.e., engage in inferential processing) which lineup member was the thief. However, imagine the same situation except the police put an innocent man in the lineup. Now when you look at the lineup you have a weak ecphoric experience but because you are motivated to make an identification you begin using non-memorial cues present in the lineup (e.g., only one member is wearing the same color jacket the thief was wearing) to infer which lineup member is the perpetrator.

To the extent that witnesses have a strong ecphoric experience, they will engage in fewer inferential processes; to the extent that witnesses have a weak ecphoric experience, they will engage in more inferential processes. Choosing and identification confidence are both partly a function of whether the two processes - ecphoric experience and inferential - cooperate (i.e., lead to the same lineup member) or compete (i.e., lead to different lineup members) with each other. Thus, two main points arise from this conceptualization: Non-memorial cues can influence choosing (as they can lead witnesses to infer who the suspect is in a lineup), and the magnitude of the influence of those nonmemorial cues is inversely proportional to the strength of the witnesses' ecphoric experience. 
The tradeoff between the witnesses' ecphoric experience (i.e., recognition) and inferential (i.e., reasoning) processing proposed by the CCC reflects a framework that several social and cognitive psychological theories propose. For instance, the outshining hypothesis (Smith, 1988) predicts that the effectiveness of environmental context cues will be dependent upon the presence (or absence) of better cues. In other words, when a person's memory is weak they will use external cues to aid in their task. However, when a person's memory is strong they will not seek external cues to aid in their task. Indeed, research shows that context reinstatement leads to better memory when a free recall task is given (a situation where the memorial task is more difficult because of the absence of cues), but does not affect memory performance when a recognition task is given (a situation where the memorial task is easier because of the presence of cues; e.g., Godden \& Baddeley, 1975, 1980; Smith, Glenberg, \& Bjork, 1978). Another example of this general framework is Festinger's (1954) social comparison theory which proposes that individuals will not seek out external comparisons to aid in their self-evaluations if their own internal standards are strong. Thus, in general the extent to which external influences impact peoples memory, self-perceptions, and/or other behavioral phenomenon seem to be inversely related to the strength of the available internal influences.

Although the CCC and Instance Theory share much of the same underlying framework, the CCC differs in some respects due mainly with its application to a lineup task. Whereas Instance Theory states automaticity is reached through the accruing of repeated interaction with a stimulus, the CCC states an ecphoric experience may develop through any processes that increases memory quality (e.g., increased exposure duration, quality of view, degree of attention allocated, etc.). Next, the strength of the ecphoric 
experience is dependent upon the quality of the witnesses' memory and the extent to which the witnesses' memorial representation of the perpetrator closely matches the perpetrator's physical appearance in the lineup. In other words, strength of the ecphoric experience is dependent upon the level of ecphoric similarity between the witnesses' memory and the perpetrator's appearance in the lineup. As this match weakens, either because of a poor memory or because the perpetrator is not in the lineup, so will the ecphoric experience. Lastly, according to the CCC, if the witness has a strong ecphoric experience it will always win; however, inferential processes still occur before any decision is made. To clarify, within this framework, an inferential process is when a witness tries to ascertain who the suspect is. Thus, the CCC proposes that regardless of the strength of the witnesses' ecphoric experience, witnesses' will usually engage in inferential processes which will either support (corroborate) or cast doubt (compete) about the veracity of the ecphoric response. Next I will discuss evidence within the literature that shows witnesses choosing behavior is driven by both the ecphoric experience and inferential processing.

Research investigating various postdictors of eyewitness accuracy (i.e., variables collected during or after the identification itself that are related to a witness's accuracy) suggest that quick, automatic responses are related to correct identifications whereas slow, deliberative responses are related to false identifications (Leippe \& Eisenstadt, 2007). Four specific postdictors have been discovered. First, accurate identifications tend to be associated with higher confidence (Sporer, Penrod, Read, \& Cutler, 1995). Second, decision time has been consistently shown to be negatively associated with accuracy (Smith, Lindsay, \& Pryke, 2000; Sporer, 1992, 1994), such that witnesses who take a 
long time to make an identification (presumably because they are using inferential processing) tend to be less accurate than those who come to a quick decision (presumably because they have a strong ecphoric experience). Third, witnesses who report having had an automatic recognition experience (i.e., strong ecphoric experience) during the lineup identification task are more likely to make accurate identifications than witnesses who report having engaged in more deliberative, process-of-elimination judgments (i.e., inferential processing; Dunning \& Stern, 1994; Dunning \& Perretta, 2002; Smith et al., 2000). Lastly, accurate witnesses (i.e., those who tended to have had a strong ecphoric experience) tend to remember fewer fillers than inaccurate witnesses, presumably because they were less likely to encode the fillers' faces (Charman \& Cahill, 2012). These findings likely all stem from a common underlying process: when a witness has a strong ecphoric experience it indicates they have likely seen that person before, thus suggesting the lineup member is the perpetrator. On the other hand, a weak ecphoric experience leads a witness to engage in inferential processing, and is thus likely to result in an inaccurate identification. Note that this is consistent with the CCC's prediction of a trade-off between ecphoric experience and inferential processes: Witnesses with a weak ecphoric experience engage in subsequent inferential processes, which can lead to false identifications.

Based upon the above data it seems clear eyewitnesses (1) engage in inferential processing and (2) the extent to which witnesses engage in inferential processing is dependent upon the strength of their ecphoric experience. Furthermore, this line of research also provides support that eyewitnesses are motivated to make a decision and if that decision does not come easy (i.e., strong ecphoric experience) they will engage in 
inferential processing in search of evidence (both memorial and non-memorial) for which lineup member they should identify.

The CCC is quite capable of explaining much of the existing data, including the findings suggesting a trade-off between the ecphoric experience and inferential processing: the fact that non-memorial cues affect choosing behavior (e.g., administrator influence; Greathouse \& Kovera, 2009; Phillips et al., 1999), that the effect of nonmemorial cues is greater when they have no other information to rely on (e.g., criminalface bias; Flowe \& Humphries, 2011), and data showing that certain cues can change the distribution of choices (e.g., administrator influence; Clark et al., 2009). In sum, by postulating that witnesses may engage in inferential processes, the CCC can account for the motivational component of a lineup task.

Thus far I have presented three theoretical explanations that may possibly account for the effect of non-memorial cues on witness choosing behavior. Each explanation makes a different prediction about how a non-memorial cue will affect witness choosing behavior. First, a criterion shift explanation would predict that the presence of a nonmemorial cue will lower witnesses' decision criterion resulting in increased choosing regardless of witnesses' ecphoric experience. Second, the reassessment of match values explanation would predict that any effect of the presence of a non-memorial cue on witness choosing will be mediated by a change in perceived similarity. Third, the inferential based framework will predict that the presence of a non-memorial cue will affect choosing rates independently of a change in perceived similarity. 


\section{Present Study}

The purpose of the present study was to provide an initial test of the inferential based framework proposed by the CCC. First, in Study 1, I examined whether mock witnesses - who lack a memory of a perpetrator - nonetheless use non-memorial based cues to infer the identity of the suspect in a lineup; this will also allow me to determine the most effective non-memorial cue to use in Study 2. Second, in Study 2, the primary goal was to examine the backbone of the CCC, by examining whether the effect of nonmemorial cues (which require inferential processing) is moderated by the strength of the witnesses' ecphoric experience. An additional goal was to test the three theoretical explanations (i.e., criterion shift, reassessment of match values, and inferential based explanation) that attempt to account for the effect of non-memorial cues on choosing behavior. Specific hypotheses and the rationale supporting each prediction will be further outlined for each Study. 


\section{STUDY 1}

Given the importance of this manipulation and the relative scarcity of past research examining this specific manipulation, the goal of Study 1 was to test whether non-memorial cues affect mock witnesses' choosing behavior. To provide a test of the CCC it was necessary to use non-memorial cues that would affect choosing rates without affecting the memorial experience of the witness. For example, having only one of the lineup members wearing similar clothing to that of the perpetrator could be used as a cue to affect witnesses’ choosing behavior. However, in this case the memory-based models could account for this effect via an increase in familiarity: Perhaps the similarity of clothing worn by the suspect produces a sense of familiarity in the witness, thus allowing memory-based theories to account for these data. Thus, the cues used in Study 1 were deliberately chosen because they are assumed to affect choosing yet are unlikely to do so by increasing familiarity.

Because the CCC predicts these cues will be most effective when the witnesses’ ecphoric experience is weak compared to when it is strong, Study 1 used a mock-witness paradigm. Doob and Kirshenbaum (1973) proposed the mock-witness paradigm to evaluate the extent to which the suspect in the lineup stands out compared to the other lineup members (i.e., lineup bias). In contrast to a real witness, a mock-witness has no memory of the perpetrator but is still asked to view a lineup and to identify the person who they think is the suspect. To aid the mock-witnesses' decision, they are given a verbal description provided by the actual witness. If the lineup is fair then the mockwitnesses’ identifications should be evenly distributed amongst the lineup members, whereas if a lineup is biased against the suspect the suspect will be identified at a rate 
above chance. I hypothesized that the presence of a cue on a lineup member will lead to increased choosing of that lineup member compared to the absence of a cue. Because the mock witnesses by definition lack a memory of the perpetrator, such a finding could only be accounted for if mock witnesses used the cue infer who the suspect is.

\section{Method}

Participants and Design. One hundred forty-six undergraduate students (68\% female; $65 \%$ Hispanic; $M_{\text {age }}=22, S D=3$ ) from a large southeastern university participated in exchange for extra credit in their psychology courses. This research was fully approved to meet all ethical standards of treatment by an institutional review board (IRB). One group of participants $(n=73)$ were shown 8 lineups, five of which had a nonmemorial cue on a randomly selected lineup member, while 3 lineups were distractors with no non-memorial cue present. A separate group of participants $(n=73)$ were shown the same 5 cued lineups except there were no non-memorial cues present.

\section{Materials}

Non-memorial cue stimuli. For this study I developed 5 non-memorial cues to assess. In essence the goal of a non-memorial cue in the lineup is to provide the witness with a cue that they could use to help guide their choosing behavior without affecting familiarity. The cues that were tested were: 1) One of the photographs had a different color background compared to the other photographs in the lineup which all had white backgrounds, 2) One of the photographs had a mug shot like background whereas the other photographs in the lineup had no backgrounds, 3) One of the photographs had a circle around its number whereas the other photographs in the lineup did not, 4) One of the photographs was slightly larger in size compared to the other photographs in the 
lineup, and 5) One of the photographs was tilted at an angle whereas the other lineup photographs were not.

Lineup construction. All lineups were constructed using a digital database of student identification photographs. Of the five critical lineups (those both groups were exposed to either containing the cue or not), two consisted of Hispanic Females, one of Hispanic Males, one of Caucasian Females, and one of Caucasian Males. Of the three distractor lineups (that were only shown to half of the participants), one consisted of Hispanic Females, one of Hispanic Males, and one of African American Females. For each lineup a mock suspect was first selected then fillers were chosen based on the similarity to that mock suspect. Lineups were shown simultaneously on a computer screen in full color in a 3 x 2 array consisting of head-and-shoulder views, wearing everyday clothing in a full-frontal view.

\section{Procedure}

Lineups were shown to two separate psychology classes at the beginning of the class. Participants were instructed that they would view a series of lineups and that for each lineup they were to choose the lineup member who best fit the description provided to them. Of note, none of the non-memorial cues manipulated affected or were related to this description. At the top of each lineup a vague description was provided consisting of ethnicity, gender, and hair and eye color. All participants’ responses were recorded before moving to the next lineup and they were kept blind as to the number of lineups they would view. For the group that saw the lineups with the non-memorial cues embedded in five of them, there was an additional three lineups (distractor lineups) with no additional cues embedded to prevent the participants from deducing the purpose of the 
study. Only those in the non-memorial cue condition were shown these distractor lineups. Once all data was recorded the participants were thanked for their time and given extra credit.

\section{Results and Discussion}

To examine the effect of the non-memorial cues on choosing I compared the rate at which the cued lineup member was chosen when the cue was present (cue condition) compared to when it was absent (control condition). Only two cues significantly increased choosing rates of the cued member. First, when the lineup member's number was circled he was chosen at a significantly higher rate (56.2\%) compared to when the cue was absent $(34.2 \%), \chi^{2}(1, N=146)=7.08, p=.008, \phi^{2}=.05$. Second, when the lineup member had a mugshot like background she was chosen at a significantly higher rate $(37.0 \%)$ compared to when the cue was absent $(13.7 \%), \chi^{2}(1, N=146)=10.46, p=$ $.001, \phi^{2}=.07$

The remaining three cues did not affect choosing rates. First, when the lineup member's photograph had a different colored background he was chosen at a similar rate (63.0\%) compared to when his background was not different (43.9\%), $\chi^{2}(1, N=146)=$ 2.78, $p=.09, \phi^{2}=.02$. Second, when the lineup member's photograph was enlarged she was chosen at a similar rate (9.6\%) compared to when her photograph was the same size as the other members $(16.4 \%), \chi^{2}(1, N=146)=1.51, p=.22, \phi^{2}=.01$. Third, when the lineup member's photograph was tilted he was chosen at a similar rate (13.7\%) compared to when his photograph was not tilted $(9.6 \%), \chi^{2}(1, N=146)=0.59, p=.44, \phi^{2}=.004$.

Based upon these results it was established that both the presence of a circle on a lineup member's number and a mugshot-like background significantly increased 
choosing rates of those lineup members compared to the absence of the cue. Thus, I showed that mock witnesses use non-memorial cues to infer the identity of the suspect in a lineup. However, it should be noted that this study does not provide any evidence as to the predictions made by the CCC because this study used mock-witnesses who by definition have no memory of the crime and who are forced to choose. On one hand, it is not all that surprising that under these contrived conditions they used the presence of a cue to aid in their lineup choice. On the other hand, the fact that not every cue we tested affected choosing rates indicates that not all cues have comparable effects. It may be that the cues that did not affect choosing (i.e., different color, enlarged, and tilted) did not allow the mock witnesses to infer who the suspect was. In contrast, the circle and mugshot-like background may have allowed the mock witnesses to infer the identity of the suspect. For example, the mock witnesses might have inferred the circle in the lineup implied that another witness already identified this person, thus implying that lineup member was the suspect. Importantly, because mock-witnesses have no memory of the perpetrator any effect of the cue on choosing rates must have been the result of an inferential process. However, these results cannot tell us how these cues will affect real witnesses who have an actual memory of the perpetrator. Thus, the purpose of Study 2 was to examine the effect of non-memorial cues on real witnesses. 


\section{STUDY 2}

As previously stated, the purpose of this study was to examine whether the effect of non-memorial cues (which require inferential processing) on witness choosing behavior is moderated by the strength of the witnesses' ecphoric experience. The strength of the witnesses' ecphoric experience depends upon the convergence of two factors. First, it depends on the strength of the initial memory of the stimulus (i.e., the perpetrator). Second, it depends on the similarity between the stimulus presented during the recognition experience (e.g., the suspect's photograph in the lineup) and the stimulus as presented during the memorial event (in this case the perpetrator's face). Thus, although ecphoric experience can be manipulated in various ways, the simplest manipulation involves presenting witnesses with either a target-present (strong ecphoric experience) or a target-absent (weak ecphoric experience) lineup (e.g., see Charman \& Wells, 2012). This manipulation is effective because it alters the level of similarity between the witness's memory of the perpetrator and the perpetrator's appearance by either including (strong ecphoric experience) or not including (weak ecphoric experience) the perpetrator in the lineup. According to the CCC, non-memorial cues will have a greater effect on eyewitness choosing behavior among witnesses who have a weak ecphoric experience (i.e., from target-absent lineups) rather than a strong ecphoric experience (i.e., from target-present lineups). Therefore, I hypothesized that the presence of a non-memorial cue will increase choosing rates of the cued member, and will do so more when witnesses have a weak ecphoric experience than a strong ecphoric experience (Hypothesis 1).

Recall that the CCC predicts that the effect of non-memorial cues on choosing behavior will occur via leading witnesses to deliberatively infer who the suspect is 
whereas the WITNESS model predicts that non-memorial cues will lead a witness to reassess the match values of the various lineup members, thus potentially changing who appears most similar to the witness's memory of the perpetrator. To tease apart these two explanations I collected similarity data of the various lineup members. It was predicted, consistent with CCC predictions, that the perceived similarity between the suspect's lineup photograph and the witness's memory of the perpetrator would not mediate the effect of the non-memorial cue on suspect identifications (Hypothesis 2).

Additionally, according to the CCC, regardless of the strength of their ecphoric experience witnesses will engage in some level of inferential processing because the importance of the decision and the lack of time constraints allows witnesses motivation and time to engage in these processes. Thus, I predicted that corroborating cues (i.e., when a deliberative cue suggests the identified lineup member) should increase confidence whereas competing cues (i.e., when a deliberative cue suggests someone other than the identified lineup member) should reduce confidence, and this effect will be greater among witnesses who have a weak ecphoric experience rather than witnesses who have a strong ecphoric condition (Hypothesis 3). Furthermore, if inferential processing is engaged in regardless of the strength of the ecphoric experience, then even when witnesses have a strong ecphoric experience, decision time should be longer for those in the cued conditions compared to the no-cue condition (Hypothesis 4).

\section{Method}

Participants and Design. Three hundred seventy six undergraduate students (64.1\% female; $62.7 \%$ Hispanic; $M_{\text {age }}=21, S D=3.33$ ) from a large southeastern university participated in exchange for extra credit in their psychology courses. This 
research was fully approved to meet all ethical standards of treatment by an IRB.

Participants were assigned randomly to conditions in a 2 (lineup type: target-present, target-absent) x 3 (non-memorial cue: cue-target, cue-filler, no-cue) between-subjects design. Lineup type refers to the presence (target-present) or absence (target-absent) of

the perpetrator. We chose to use the circle as the non-memorial cue in the present study because, unlike the mug-shot like background cue, the circle cue does not alter the actual photographs in the lineup. Thus, any effect the circle had on choosing behavior would be difficult to account for with an increase in familiarity explanation. Non-memorial cue refers to the placement of the cue (or lack thereof) within the lineup. In the cue-target condition, participants viewed a lineup in which a co-witness had ostensibly identified the perpetrator's photograph (target-present lineups) or the innocent suspect's photograph (target-absent lineups) by circling that lineup member’s number. In the cue-filler condition, participants viewed a lineup in which a co-witness had ostensibly identified one of the fillers in the lineup by circling that lineup member's number (the cue will be rotated amongst the two best alternative fillers). Lastly, in the no-cue condition, participants viewed a lineup without a non-memorial cue present.

\section{Materials}

Mock crime video. The mock-crime video portrayed a young Hispanic male stealing money from a purse on a table outside of a University building. The video was 53s in length with the perpetrator's face in view for 13s. All witnesses viewed the same video together on a computer screen.

Lineup construction. Fillers were chosen from a digital database of student identification photographs. Fillers were chosen based on their match to the perpetrator on 
various characteristics (gender, age, skin tone, hair color and length, and facial hair). Six fillers were chosen based on the aforementioned characteristics. Target-absent lineups were composed of these six fillers whereas target-present lineups were constructed by replacing filler \#2 with the target. Thus, filler \#2 served as our a priori innocent suspect in target-absent lineups. Research using this identical lineup indicated that the target-present lineup had an effective size of 4.0 (Charman \& Cahill, 2012).

The non-memorial cue manipulation consisted of providing the participants in the cued conditions with ostensible co-witness information in the form of a circle on one of the lineup member's number, thus allowing a witness to infer that another witness had identified the cued member as the thief from the video. Several deceptive steps, described in detail below in the procedure section, were taken to ensure the participants believed that the circle was made by a fellow witness and not the researcher. There were four lineup variations for each lineup type (i.e., present, absent): one lineup with an "erased” circle on the target (or innocent suspect) photo’s number (cue-target condition), two lineups with the "erased" circle rotated between the two best alternative fillers' numbers (cue-filler condition), and one lineup with no cue present (no-cue condition).

Furthermore, the position of the target (or innocent suspect) was rotated between position two and five. Thus, in total there were 16 lineup variations. Lineup members were shown simultaneously on a sheet of paper in full color in a 3 x 2 array consisting of head-andshoulder views, wearing everyday clothing in a full-frontal view.

\section{Procedure}

Upon arrival participants in groups of 2 or 3 (with 70.2\% of participants being in groups of 3), viewed a short video on a computer monitor. Upon completion of the video 
participants were told the man in the video was stealing money from a purse and they were now witnesses to the crime. Furthermore, they were told the purpose of the experiment was to examine the consistency of co-witnesses' memory by having them answer the same questions about the crime they just witnessed.

Next, they were told they would all be shown the same lineup and asked to identify the thief from the video. During these instructions the researcher showed the participants the back of the purportedly only lineup which had a solid green paper taped to the back. In reality all lineups had this same solid green paper taped to the back. This was done to further support the deception that all witnesses would be viewing the same lineup. They were then told they would work on an anagram task separately for several minutes until the researcher was ready to test them. But before separating them they were instructed to draw a number from a hat which would indicate the order in which they would make their lineup decisions; in reality all the numbers were a "3”, thus making them believe they would be the last witness to view the lineup. To ensure the deception they were told not to reveal their number to each other.

Once separated the researcher entered each room and asked them which number they drew. After the participants worked on the anagram task for 5-min, the researcher assigned participants randomly to one of the conditions and then chose randomly the order the participants were tested. Upon entering the room, the researcher thanked them for their patience while they tested the other participants first; again this was to reinforce the deception. The researcher was holding up a clipboard with the lineup on the bottom such that the back of the lineup, with the solid green paper on the back, was in clear view of the participant while they provided lineup instructions. The researcher provided the 
instructions for the lineup task including unbiased lineup instructions (e.g., the perpetrator may or may not be in the lineup and a "not there" response is acceptable; Malpass \& Devine, 1981). Furthermore, to ensure that participants were sufficiently motivated to take the lineup task seriously they were told that if they made the correct lineup decision they would receive an extra point of course credit. (In reality, regardless of the accuracy of their decision they received the extra point of credit.) Before the researcher showed the participant the lineup they glanced at the lineup and ostensibly noticed something wrong with the lineup. They apologized to the participant and picked up an eraser from the desk and proceeded to erase something on the lineup. Importantly, the participant did not see what the researcher was erasing and in fact the researcher actually was not erasing anything. Again, this was done to reinforce the deception that the circle in the lineup was from a fellow co-witness and not the researcher. Lastly, the participant was shown one of the aforementioned lineups and their identification and decision time (measured using a digital stopwatch) was assessed. Immediately following their identification participants provided a confidence judgment. Specifically, they were asked, On a scale from 0 (Not Confident at all) to 100 (Completely Confident) how confident are you in your lineup decision?

Next, participants completed a memory questionnaire that assessed the remaining dependent measures. The order of the questionnaire was as follows. First, participants viewed the lineup presented to them previously and, for each lineup member, indicated how "physically similar" the lineup member was to their memory of the thief from the video on a Likert-type scale ranging from 1 (Not at all similar) to 10 (Very Similar). Next, participants completed a series of open-ended questions assessing the processes 
underlying their lineup identification decisions, their perceived impact of the nonmemorial cues on their decision making, and their motivations underlying their identification decision (e.g., Please describe why you made your lineup decision. That is, why did you choose X lineup member or why did you choose the "not there option"). See Appendix for a complete list of questions.

Next, participants completed questions assessing the automaticity/deliberativeness of their identification experience, as well as whether they engaged in absolute or relative judgment strategies, via their endorsement of various statements that described processes in which they may have engaged. Participants were allowed to endorse having used as few or as many of these processes as they wished to describe how they reached an identification decision. Participants then completed questions assessing their self-reported viewing conditions (e.g., "How clear is the image you have in your memory of the target photo? "). See Appendix for a complete list of questions. Lastly, participants completed a demographic questionnaire (e.g., age, gender, etc.).

\section{Results}

Manipulation Check. Prior to examining the main hypotheses we first needed to examine the effectiveness of the ecphoric experience manipulation. Several lines of evidence, detailed below, were used to independently examine the effectiveness of the ecphoric experience manipulation.

Similarity ratings. The extent to which a witness had a strong ecphoric experience depends upon the quality of memory and the level of similarity between the witness's memory of the perpetrator and the perpetrator's lineup photograph. Thus, manipulating lineup type (target-present vs target-absent) should have led to changes in 
the level of ecphoric similarity reported by witnesses. To more precisely assess the effect of lineup type on ecphoric similarity only witnesses in the control group (i.e., those who did not receive a non-memorial cue) were included in this analysis. In support, witnesses in the target-present condition rated the suspect's photograph as significantly more similar $(M=7.24, S D=2.52)$ compared to witnesses in the target-absent condition $(M=$ 3.34, $S D=2.57), t(122)=8.51, p<.001, \eta^{2}=.37$.

Postdictor variables. Research consistently shows that witnesses who make accurate identifications tend to make quicker decisions, report having had an automatic recognition experience, and have a higher level of confidence-all indicative of a strong automatic experience (Charman \& Cahill, 2012; Kelley \& Lindsay, 1993; Shaw, 1996). Given the assumption that the postdictors are effective because they reflect the strength of the ecphoric experience a witness had, differences in these postdictors across lineup type would be indicative of a successful manipulation of ecphoric experience. Of note, only witnesses that made an identification were included in these analyses because postdictors have only been found to postdict accuracy in choosers. First, witnesses in the target-present condition had a marginally significantly higher level of confidence $(M=$ $70.79, S D=18.66)$ compared to witnesses in the target-absent condition $(M=66.58, S D$ $=20.75), t(271)=1.75, p=.08, \eta^{2}=.01$. Second, witnesses in the target-present condition took significantly less time to make a decision $(M s=19.22, S D=13.95)$ compared to witnesses in the target-absent condition $(M s=25.14, S D=17.79), t(271)=$ $-3.08, p=.002, \eta^{2}=.03$. Third, witnesses in the target-present condition reported a higher level of automaticity $(M=0.65, S D=0.74)$ compared to witnesses in the target-absent 
condition $(M=0.42, S D=0.65), t(271)=2.67, p=.008, \eta^{2}=.03$. As expected, the aforementioned analyses indicated the manipulation of automaticity was successful.

\section{Choosing Behavior}

One of the main predictions of the CCC was that the presence of a non-memorial cue would increase choosing rates of the cued member, and would do so more when witnesses have a weak ecphoric experience (Hypothesis 1). Because the hypothesis specifically predicts that the presence of a non-memorial cue will lead to an increase in choosing rates of the cued lineup member, separate analyses were conducted for suspect identifications and filler identifications. Thus, multiple binary hierarchical-logistic regression analyses were conducted examining the effect of the non-memorial cue and lineup type on the various identification choices (i.e., suspect and filler identifications).

Suspect identifications. To examine the effect of the non-memorial cue for those in the cue-target condition I regressed the likelihood of making a suspect identification (i.e., chose the target from the target-present lineup or chose the innocent suspect from the target-absent lineup) on non-memorial cue (cue-target, no-cue) and lineup type (target-present, target-absent).

Results indicated the main effect of non-memorial cue on suspect identifications was not significant, Wald $(1)=0.11, p=.74, O R=0.92$. However, witnesses were more likely to identify the suspect in the target-present condition (65.6\%) compared to the target-absent condition (17.2\%), Wald(1) = 52.16, $p<.001$, OR = 9.22. More importantly, results indicated the inclusion of the interaction term significantly improved model fit, $\chi^{2}(1, N=244)=12.54, p<.001$. The model correctly classified $74.2 \%$ of witnesses' into suspect identifiers (or not) and accounted for a large amount of variance 
(Nagelkerke $\mathrm{R}=.35$ ). Individually, the model indicated the interaction term accounted for a unique amount of variance, $\operatorname{Wald}(1)=10.90, p=.001, O R=10.31$. For those in the target-absent condition, simple main effects indicated witnesses were significantly more likely to identify the suspect in the cue-target condition (26.6\%) compared to the no-cue condition (6.9\%), Wald(1) $=7.21, p=.007, \mathrm{OR}=4.88$. In contrast, for witnesses in the target-present condition, simple main effects indicated witnesses were significantly less likely to identify the suspect in the cue-target condition (56.4\%) compared to the no-cue condition $(73.1 \%)$, Wald $(1)=3.71, p=.05, O R=0.47$. See Table 1 for probability and odds of suspect identification by condition.

Clearly, the presence of a non-memorial cue affected choosing behavior and was moderated by the ecphoric experience. Consistent with predictions the presence of a nonmemorial cue increased suspect identifications in target-absent lineups. However, unexpectedly the presence of a cue decreased suspect identifications in target-present lineups. I will return to this point later. An important question is how is the non-memorial cue affecting suspect identifications among witnesses? There are two possible explanations.

Redistribution of identifications. The first explanation is that the non-memorial cue led witnesses who would have made a filler identification to identify the suspect. In other words, the non-memorial cue redistributed the identifications of witnesses who were already inclined to choose. To examine this explanation I regressed the likelihood of making a suspect identification (i.e., chose the target from the target-present lineup or chose the innocent suspect from the target-absent lineup) on non-memorial cue (cue- 
target, no-cue) and lineup type (target-present, target-absent), but only included witnesses who made a lineup identification (i.e., choosers only).

Results indicated the main effect of non-memorial cue on suspect identifications was not significant, Wald(1) $=0.11, p=.74, O R=0.91$. However, witnesses were more likely to identify the suspect in the target-present condition (76.9\%) compared to the target-absent condition (28.8\%), Wald(1) $=36.63, p<.001, O R=8.65$. More importantly, results indicated the inclusion of the interaction term significantly improved model fit, $\chi^{2}(1, N=177)=8.33, p<.001$. The model correctly classified $74.6 \%$ of witnesses' suspect identifications and accounted for a large amount of variance (Nagelkerke $\mathrm{R}=$.33). Individually, the model indicated the interaction term accounted for a unique amount of variance, Wald(1) $=7.62, p=.006, O R=8.55$. For those in the target-absent condition, simple main effects indicated choosers were significantly more likely to identify the suspect in the cue-target condition (40.5\%) compared to the no-cue condition (12.9\%), Wald(1) $=6.02, p=.01, O R=4.60$. In contrast, for witnesses in the target-present condition, simple main effects indicated witnesses were equally likely to identify the suspect in the cue-target condition (70.5\%) compared to the no-cue condition (81.7\%), Wald(1) $=1.77, p=.18, O R=0.54$. See Table 1 for probability and odds of suspect identification by condition. Thus, the non-memorial cue changed the distribution of choices in target-absent but not target-present lineups.

Increase in choosing rates. The second explanation is that the non-memorial cue leads witnesses who would not have made an identification to now identify the suspect. To examine this explanation I regressed the likelihood of making an identification 
(choice) on non-memorial cue (cue-target, no-cue) and lineup type (target-present, targetabsent).

Results indicated there was a significant main effect of lineup type on choice, such that witnesses were significantly more likely to make an identification in the targetpresent condition (85.3\%) compared to the target-absent condition $(59.8 \%)$, Wald $(1)=$ $18.54, p<.001, O R=3.90$. The effect of cue on choice was not significant, Wald(1) $=$ $0.01, p=.93, O R=0.97$. See Table 2 for probability and odds of making an identification by condition. Furthermore, results indicated the inclusion of the interaction term significantly improved model fit, $\chi^{2}(1, N=244)=4.01, p=.05$. The model correctly classified 72.5\% of participants' choice decisions and accounted for a large amount of variance (Nagelkerke $\mathrm{R}=.14$ ). Individually, the model indicated the interaction term significantly accounted for a unique amount of variance, Wald(1) $=3.92, p=.05$, OR $=$ 3.56. For witnesses in the target-present condition, simple main effects indicated witnesses were equally likely to make a choice in the cue-target condition (80.0\%) compared to the no-cue condition (89.6\%), Wald(1) $=2.13, p=.15, \mathrm{OR}=0.47$. Similarly, for witnesses in the target-absent condition, simple main effects indicated witnesses were equally likely to make a choice in the cue-target condition (65.6\%) compared to the no-cue condition (53.5\%), Wald(1) $=1.87, p=.17, \mathrm{OR}=1.66$.

The above analyses indicated that the effect of the non-memorial cue on suspect identifications was the result of the non-memorial cue redistributing the identifications of choosers, rather than leading non-choosers to identify the suspect.

Filler identifications. Because I hypothesized the non-memorial cue should lead to an increase of the cued lineup member and I counterbalanced the cue among two fillers 
(filler 1 or filler 6), two separate analyses were needed to examine the effect of the nonmemorial cue on filler identifications. That is, when filler 1 was cued I regressed filler 1 identifications (i.e., chose filler 1) on non-memorial cue (cue-filler, no-cue) and lineup type (target-present, target-absent) and when filler 6 was cued we regressed filler 6 identifications (i.e., chose filler 6) on non-memorial cue (cue-filler, no-cue) and lineup type (target-present, target-absent).

Filler 1 identifications. Results indicated the main effect of non-memorial cue on filler 1 identifications was not significant, Wald(1) $=0.53, p=.47, O R=1.43$. However, witnesses were more likely to identify filler 1 in the target-absent condition (17.4\%) compared to the target-present condition (3.0\%), Wald(1) $=8.56, p=.003, \mathrm{OR}=6.67$. The interaction term could not be computed because no witnesses in the cue-filler/targetpresent condition selected filler 1 (see Table 3 for probabilities) which makes logistic regression problematic when you have categorical predictors with limited cases in each category (Tabachnick \& Fidell, 2013). To examine the effect of the non-memorial cue on filler 1 identifications I conducted a chi-square analysis for only those witnesses in the target-absent condition, where enough cases were present in each category. Results indicated witnesses in the cue-filler condition (23.5\%) and the no-cue condition (13.8\%) were equally likely to identify filler $1, \chi^{2}(1, N=92)=1.41, p=.23, \phi^{2}=.01$.

Filler 6 identifications. Results indicated the main effect of non-memorial cue on filler 6 identifications was not significant, Wald(1) $=0.21, p=.65, O R=1.29$. However, witnesses were more likely to identify filler 6 in the target-absent condition (15.5\%) compared to the target-present condition $(1.9 \%)$, Wald(1) $=8.73, p=.003$, OR $=9.90$. Again, the interaction term could not be computed because of limited cases in the cue- 
filler/no-cue target-present conditions (see Table 3 for probabilities). To examine the effect of the non-memorial cue on filler 6 identifications I conducted a chi-square analysis for only those witnesses in the target-absent condition, where enough cases were present in each category. Results indicated witnesses in the cue-filler condition (19.2\%) and the no-cue condition (13.8\%) were equally likely to identify filler $6, \chi^{2}(1, N=84)=$ $0.41, p=.52, \phi^{2}=.005$. Although the data do not show a significant effect of the nonmemorial cue on filler identifications, the direction of the effects are in the predicted direction and sample size is certainly limiting the power of these analyses.

In sum, the choosing behavior data indicated that the non-memorial cue affected suspect identifications and that the effect seems to be the result of the non-memorial cue altering the distribution of choices as opposed to increasing choosing overall. Recall, the criterion shift explanation would predict the presence of a non-memorial cue would affect choosing behavior by lowering a witness's decision criterion. However, the aforementioned data is inconsistent with this prediction for two reasons. First, if the effect of the non-memorial cue on suspect identifications was the result of lowering a witness's decision criterion then the presence of the cue should have led to increased suspect identifications across both lineup types (i.e., target-present and target-absent). Second, altering a witness's decision criterion will either increase (when it is lowered) or decrease (when it is raised) choosing rates, but importantly, it will not alter the distribution of lineup choices. That is, the lineup member who is the best match to the witness's memory will always be picked at the highest rate regardless of a witness's decision criterion. 


\section{Similarity Ratings}

Recall, that the CCC predicts the effect of non-memorial cues on choosing behavior will occur via leading witnesses to deliberatively infer who the suspect is whereas the WITNESS model predicts that non-memorial cues will lead a witness to reassess the match values of the various lineup members, thus potentially changing who appears most similar to the witness's memory of the perpetrator. Consistent with CCC predictions, I hypothesized the perceived similarity between the suspect's lineup photograph and the witness's memory of the perpetrator would not mediate the effect of the non-memorial cue on suspect identifications (Hypothesis 2).

To examine whether perceived similarity between the suspect’s lineup photograph and the witness's memory of the perpetrator mediated the effect of the non-memorial cue on suspect identifications I used a robust modeling tool called PROCESS (Hayes, 2013). Process uses the bootstrapping method (1,000 bootstrap samples in the current analysis) to generate bias-corrected confidence intervals for testing the indirect effects (i.e., the effect of the non-memorial cue on suspect identifications through perceived suspect similarity). Of note, because earlier analyses showed that the effect of the non-memorial cue on suspect identifications was moderated by lineup type I conducted a mediation for each lineup type. Thus, the models consisted of the predictor variable $X$ (non-memorial cue: cue-target, no-cue), the mediator variable $M$ (perceived similarity of the suspect), and the outcome variable $Y$ (suspect identification: yes, no) for both target-present and target-absent lineups, separately.

Target-present mediation model. Results indicated $(N=121)$ the total effect of the non-memorial cue on suspect identifications was marginally significant, $b=-0.72$, $S E$ 
$=.39, p=.06$ (see Figure 1). Of note, current thinking about mediation does not require a statistically significant total effect for mediation to be present (Hayes, 2013). Thus, witnesses were less likely to identify the suspect in the cue-target condition compared to the no-cue condition. The direct effect of the non-memorial cue on suspect identifications, while controlling for the perceived similarity of the suspect, was not statistically significant, $b=-0.79, S E=.59, p=.17$. Furthermore, the indirect effect of the non-memorial cue on suspect identifications through the perceived similarity of the suspect was not statistically different from zero as evidenced by a $95 \%$ bias-corrected bootstrap confidence interval (bootLLCI $=-1.58$ to bootULCI $=0.29$ ), $b=-0.60, S E=$ .49. Consistent with predictions, the effect of the non-memorial cue on suspect identifications was not mediated by the perceived similarity of the suspect; witnesses in the cue-target condition did not perceive a significantly different level of similarity between the suspect and the perpetrator than witnesses in the no-cue condition, $b=-0.69$, $S E=.51, p=.17$. In sum, the current pattern of data support the predictions of the WITNESS model and not the CCC.

Target-absent mediation model. Results indicated $(N=122)$ the total effect of the non-memorial cue on suspect identifications was statistically significant, $b=1.59, S E$ $=.59, p=.007$. Thus, witnesses were more likely to identify the suspect in the cue-target condition compared to the no-cue condition. The direct effect of the non-memorial cue on suspect identifications, while controlling for the perceived similarity of the suspect, was statistically significant, $b=1.38, S E=.67, p=.04$. Furthermore, the indirect effect of the non-memorial cue on suspect identifications through the perceived similarity of the suspect was statistically different from zero as evidenced by a 95\% bias-corrected 
bootstrap confidence interval ( $b o o t L L C I=0.05$ to boot $U L C I=1.41$ ), $b=0.62, S E=.35$. Again consistent with predictions, the effect of the non-memorial cue on suspect identifications was only partially mediated by the perceived similarity of the suspect. Specifically, witnesses in the cue-target condition perceived the suspect as more similar to their memory of the perpetrator, which in turn influenced suspect identifications. Witnesses who rated the suspect as more similar to their memory of the perpetrator were more likely to identify the suspect. However, because this was only a partial mediation, this suggests that the cue's effect on suspect identifications was also being driven by an inferential process. In sum, the current pattern of data support the predictions of both the CCC and the WITNESS model.

\section{Confidence}

The CCC makes specific predictions regarding the effect of the non-memorial cue on witness confidence levels. Recall that when the non-memorial cue corroborates the witness's identification decision (i.e., when their identification was of a cued lineup member) this should increase confidence, whereas when the non-memorial cue competes with the witness's identification decision (i.e., when their identification was of a noncued lineup member) this should decrease confidence. Both of these effects should be greater in the weak ecphoric experience condition than the strong ecphoric experience condition (Hypothesis 3).

To examine this prediction I conducted a one-way between-subjects ANOVA. To establish whether the non-memorial cue was corroborating (cue-target) or competing (cue-filler) with witnesses' identification decision only suspect identifiers were included in this analysis. Also, because so few witnesses identified the suspect in the cue- 
filler/target-absent $(n=3)$ and no-cue/target-absent $(n=4)$ conditions only witnesses in the target-present condition were included in this analysis. Thus, I examined the effect of a corroborating and competing cue by examining the effect of the non-memorial cue (cue-target, cue-filler, no-cue) on confidence, including only target-present suspect identifiers in the analysis.

Results indicated there was a significant effect of non-memorial cue on confidence, $F(2,122)=3.84, p=.02, \eta^{2}=.06$. Tukey HSD tests indicated mean confidence in a suspect identification was significantly greater for witnesses in the cuetarget condition $(M=77.90, S D=15.96)$ versus witnesses in the cue-filler condition $(M=$ 67.40, $S D=16.80), p=.03$. However, all other comparisons were non-significant (see Table 4 for descriptive statistics), although the means were trending in the predicted direction. One possible factor contributing to the non-significance of these results is the significant amount of variation within each group. Also, remember the CCC predicts the effect of the non-memorial cue on confidence would be stronger in the weak ecphoric experience condition (target-absent) rather than the strong ecphoric experience condition (target-present). Thus, only being able to assess these effects in the strong ecphoric experience condition (because of sample size issues in target-absent lineups), makes it more difficult to reveal any effects. Regardless, these results support the CCC’s predictions regarding the corroborating/competing nature of the non-memorial cue on confidence reports.

\section{Decision Time}

The CCC predicts that even when witnesses have a strong ecphoric experience, witnesses will still engage is some level of inferential processes (Hypothesis 4). Thus, it 
was predicted that the presence of a non-memorial cue would significantly increase decision time but that this effect would be greater in the target-absent condition than the target-present condition. Because this prediction does not specify differential effects for the non-memorial cue conditions (i.e., cue-target, cue-filler) on decision time, I collapsed across the two cued conditions to make a combined cue condition (i.e., cue-target and cue-filler were combined into one condition). To test this prediction I conducted a 2 (lineup type: target-present, target-absent) x 2 (non-memorial cue: cue-present, no-cue) between-subjects factorial ANOVA.

To correct for non-normality decision time was transformed using a logarithm function. Also, I removed several significant outliers (i.e., cases that were more than three standard deviations from the mean). In total four cases were removed: one from the target-present/cue-present condition, two from the target-present/no-cue condition, and one from the target-absent/no-cue condition.

Results indicated the mean decision time was significantly greater for witnesses in the cue-present condition $\left(M_{S}=24.28, S D=17.55\right)$ versus witnesses in the no-cue condition $(M=20.68, S D=17.75), F(1,368)=4.59, p=.03, \eta_{\mathrm{p}}^{2}=.01$. The mean decision time was significantly lower for witnesses in the target-present $\left(M_{s}=19.48, S D\right.$ $=14.53)$ versus witnesses in the target-absent condition $\left(M_{s}=26.91, S D=19.81\right), F(1$, $368)=16.65, p<.001, \eta_{\mathrm{p}}^{2}=.04$. Last, the interaction effect was not significant, $F(1$, 368) $=0.16, p=.69, \eta_{\mathrm{p}}{ }^{2}<.001$. See Table 5 for descriptive statistics for each condition. In sum, these results provide partial support for my hypothesis. The presence of a cue did increase decision time, however, the effect was not moderated by lineup type. 


\section{DISCUSSION}

The main purpose of this study was to test whether witness choosing behavior is driven simply by memorial factors or by a combination of both memorial factors and non-memorial inferential processes. I also examined whether the effect of non-memorial cues on choosing behavior would be dependent upon the strength of the witnesses' ecphoric experience. Data across two studies indicated that witness choosing behavior was driven not only by memorial factors, but also by non-memorial factors as well, and importantly, that the effect of non-memorial factors was moderated by the strength of witnesses’ ecphoric experience. Study 1 showed that mock-witnesses, who have no actual memory of the perpetrator, engaged in an inferential process by using the presence of a non-memorial cue in the lineup to help guide their choosing behavior. However, the fact that these mock-witnesses, by definition, do not actually have a memory of the perpetrator prevents any conclusions from being drawn about how real witnesses' choosing behavior will be affected by such non-memorial cues. The findings from study 2 provided a stronger test of how real witnesses' choosing behavior is affected by nonmemorial cues.

\section{Choosing Behavior}

The presence of the non-memorial cue on the target significantly increased suspect identifications compared to its absence, but only when the witness had a weak ecphoric experience (i.e., target-absent condition). In fact, the odds of identifying the suspect were nearly five times greater when the non-memorial cue was on the target compared to when it was not on the target. Interestingly, when the witness had a strong ecphoric experience (i.e., target-present condition) the presence of the non-memorial cue 
on the target significantly decreased suspect identifications compared when there was no non-memorial cue present. The odds of identifying the target were about half as great when the non-memorial cue was on the target compared to when it was not on the target. Consistent with predictions, these effects indicate the effect of the non-memorial cue on choosing behavior was greater when the witness had a weak ecphoric experience compared to a strong ecphoric experience.

Whereas the non-memorial cue and lineup type combined to affect suspect identifications, the non-memorial cue, either alone or in combination with lineup type, did not affect filler identifications. One possible explanation for this null effect is that witnesses were less likely to report noticing the cue when it was on a filler (46\%) versus when it was on the target (71\%). Obviously for the non-memorial cue to be effective it must be noticed by witnesses; had more witnesses noticed the cue on the filler, I may have observed a significant effect on filler identifications.

Nonetheless, the effect of a non-memorial cue on suspect identifications was greater when witnesses had a weak ecphoric experience. An important questions remains: Which theoretical explanation(s) (i.e., criterion shift, reassessment of match values, or inferential-based) can best account for the current data?

\section{Theoretical Frameworks}

Clearly the data in the present study indicated witnesses' choosing behavior was driven by both memorial (e.g., strength of the witnesses' ecphoric experience) and inferential (e.g., the presence of the non-memorial cue) processes. Three theoretical explanations have been proposed to account for eyewitness choosing behavior. Because each explanation predicts that the effect of non-memorial cues on choosing behavior will 
result in a specific pattern of choosing behavior, direct comparisons among the explanations can be made to assess which theoretical perspective can best account for the data.

Criterion shift. The first explanation attempts to account for non-memorial processes via a change in a witness's decision criterion. For instance, the aforementioned cognitive models (i.e., dual-process recognition models and SDT) and the WITNESS model predict that the presence of a non-memorial cue would lead witnesses to lower their decision criterion compared when there is no non-memorial cue, resulting in an increase in choosing rates overall. And since the target should tend to be the best match to a witness's memory, then a lowered decision criterion would result in an increase in target identifications in particular. This is because a downward criterion shift would lead low confidence witnesses to choose more often but it would not alter which lineup member they would choose. Three specific patterns of data exist within the current study that are inconsistent with a criterion shift explanation.

First, the presence of a non-memorial cue on the target resulted in opposite effects on suspect identifications across lineup type. Specifically, a non-memorial on the target decreased suspect identifications from target-present lineups but increased suspect identifications from target-absent lineups. This pattern is inconsistent with a criterion shift because lowering a witness's criterion will lead to increased choosing in both targetpresent and target-absent lineups. And because the target will tend to be the best memorial match this will result in an increase in suspect identifications in both lineup types. 
Second, if the presence of a non-memorial cue affected suspect identifications via a criterion shift then they would have changed choosing rates. Inconsistent with this explanation results indicated the presence of a non-memorial cue on the target did not affect choosing rates compared to its absence for either witnesses who viewed a targetabsent or target-present lineup.

Third, the findings indicated that the non-memorial cue changed the distribution of responses: Witnesses who would have identified a filler instead identified the target when the target was cued. In other words, the cue changed the distribution of identifications among choosers. This is inconsistent with a criterion shift explanation: A criterion shift can explain a change in the proportion of witnesses who make an identification, but cannot account for a change in who witnesses identify.

Reassessment of match values. The second theoretical framework predicts that the presence of a non-memorial cue will lead witnesses to reassess the importance of certain matching and mismatching facial features leading witnesses to alter which lineup member is the best match to their memory of the perpetrator (Clark et al., 2009). In other words, this prediction can account for data showing an increase in suspect identifications from target-absent lineups as well as a concomitant decrease in suspect identifications from target-present lineups. For example, it could be that in target-absent lineups the nonmemorial cue on the target led witnesses to reassess the match values, increasing the perceived match of the target and their memory of the perpetrator, and resulting in increased choosing of the suspect. In contrast, it could be that in target-present lineups the non-memorial cue on the target led witnesses to reassess the match values, decreasing the perceived match of the target and their memory of the perpetrator, and resulting in 
decreased choosing of the suspect. This framework thus appears consistent with the choosing data. Importantly, for this prediction to be supported by the data witnesses’ perceived similarity of the suspect must at a minimum partially mediate the effect of the non-memorial cue on suspect identifications. Mediation analyses provided partial support for this framework. Specifically, suspect similarity did not mediate the effect of the nonmemorial cue on suspect identifications for witnesses in the target-present condition but did partially mediate the effect in target-absent lineups. Thus, although it appears the effect of the non-memorial cue on suspect identifications may be partly the result of a reassessment of match values, at least for target-absent lineups, this framework cannot fully explain the current pattern of data.

Inferential based framework. According to the CCC, witness choosing behavior will be driven by both memorial and non-memorial factors, with the effect of nonmemorial cues being moderated by the ecphoric experience of the witness. Importantly, unlike the re-assessment of match values framework, the CCC predicts that the effect of a non-memorial cue will be partly driven by an inferential process. That is, the nonmemorial cue will not only affect choosing behavior by altering a witness's perceived similarity between a lineup member and their memory of the perpetrator, but will also do so via an inferential deliberative process. For example, a witness may infer that the circled lineup member is likely the perpetrator because one of the other witnesses already identified him.

Mediation analyses indicated that the effect of the non-memorial cue on suspect identifications in target-absent lineups was only partly accounted for by similarity ratings and the effect of the non-memorial cue on suspect identifications in target-absent lineups 
was not mediated by similarity ratings. This suggests that the non-memorial cue is affecting choosing behavior through some other process besides a reassessment of match values. The pattern of data in both target-present and target-absent lineups can be explained via the inferential based explanation proposed by the CCC, which explains the observed data in the following way.

First, witnesses in the target-absent condition tended to have a weak ecphoric experience which led them to engage in inferential processing to aid their decisionmaking. This would have led them to notice that one of the lineup members was circled, which may result in a reassessment of the similarity between the cued lineup member and their memory of the perpetrator. However, the re-weighting of certain features may not always provide enough of a change in similarity to provide enough basis to identify this individual. Witnesses may also have then searched for non-memorial cues to help them determine the identity of the suspect in the lineup. They may have reasoned that because lineup member two was circled, that another witness identified that lineup member, and therefore inferred that he must be the perpetrator.

Second, witnesses in the target-present condition tended to have a strong ecphoric experience which led them to engage in less inferential processing to aid their decisionmaking. This would have led them to notice that one of the lineup members was circled, which may result in a reassessment of the similarity between the cued lineup member and their memory of the perpetrator. But because these witnesses tended to have a strong ecphoric experience the presence of a non-memorial cue on the target would not likely alter similarity ratings. At this point, the CCC would predict witnesses searched for other non-memorial reasons to aid in their decision making. Again, I found evidence for this. 
Witnesses who had a strong ecphoric experience reasoned that because lineup member two was circled this must be a trick and thus were less likely to choose. This latter finding, although unexpected, is still consistent with the inferential based framework. One possible explanation is that witnesses in the target-present condition, who are more likely to have a strong ecphoric experience, could be experiencing a form of psychological reactance (Brehm, 1966). Psychological reactance theory states that when an individual's freedom is threatened they will react by rebelling against that threat. Applied to these data, when the target is in the lineup witnesses have a strong ecphoric experience and want to choose the target. However, the presence of a non-memorial cue on the target may lead some witnesses to infer that their freedom to choose who they want is being threatened and thus experience reactance thereby resisting the perceived influence of the non-memorial cue, and as a result, choose to identify another lineup member. If true, this is consistent with the idea that witnesses engaged in an inferencebased process: a cue may have led them to infer that the cued suspect could not be the target.

Decision time and confidence. Aside from the choosing behavior data, the predictions regarding the effect of the non-memorial cue on both decision time and witness confidence made by the CCC were generally supported. First, when a nonmemorial cue was present witnesses took significantly more time to make a decision compared to when there was no cue. Second, when witnesses identified the suspect they reported a significantly higher level of confidence when the non-memorial cue was on the target compared to when the non-memorial cue was on a filer. These findings both provide further support for the inferential based framework proposed by the CCC. 
Clearly, the decision criterion shift explanation is unable to account for the data. The re-assessment of match values explanation was able to account for some of the data, but the CCC appears to provide the best fit for the data. Of note, the CCC and the WITNESS model are not necessarily exclusive, and can in fact be reconciled. For example, because the WITNESS model is a mathematical model it is relatively simple to incorporate the role that inferential based processing has on choosing behavior by adding a parameter to account for it within the model (although it currently has yet to do so). However, some important differences exist that I argue should lead researchers to prefer the CCC model.

First, the CCC offers a more general framework for researchers to work with because it makes the same predictions as the WITNESS model when there are no nonmemorial cues to drive inferential processing. Note that the WITNESS model was derived mostly by data obtained from studies in which the researchers deliberately avoided adding any non-memorial cues in the lineups as to the identity of the suspect. The WITNESS model is able to account for these data fairly well; however, I argue that when non-memorial cues do exist, the CCC does a better job accounting for their effects. Second, compared to the WITNESS model, the CCC provides more specific explanations for the effect of manipulations on other witness-related variables (e.g., confidence, decision time, etc.). Although the WITNESS model can be extended to account for these outcomes variables, it currently focuses primarily on choosing behavior, in contrast to the CCC, which accounts for both choosing and confidence. Third, the WITNESS model cannot fully account for the current data. For example, the WITNESS model predicts the effect of non-memorial cues on choosing behavior occurs via a re-assessment of match 
values. However, the effect of the cue in target-present data was not explained via a reassessment of match values. It appears that the effect of the cue, at least in target-present lineups, was the result of a purely inferential process. Fourth, the CCC is able to account for choosing behavior of both actual witnesses and mock-witnesses whereas the WITNESS model cannot account for mock-witness choosing behavior because it relies on match values.

A good scientific theory needs to not only make novel predictions and drive future research but it must also account for existent data and the CCC is able to do so. First, clothing bias (i.e., when only one of the lineup members is dressed similarly to how the perpetrator was at the time of the crime) has been demonstrated to increase false identifications without affecting correct identifications (Lindsay, Wallbridge, \& Drennan, 1987). According to the CCC, witnesses in the target-present condition will not be affected by the clothing bias because they have a strong ecphoric experience, resulting in less reliance on inferential processing. However, those in the target-absent lineup should have a relatively weak ecphoric experience and should therefore search for non-memorial information, using an inferential process to aid their decision-making. Thus, according to the CCC the negative effect that clothing bias has on false identifications is the result of an inferential process. Accordingly, the CCC would predict that preventing witnesses’ ability to engage in an inferential process should mitigate the negative effect of clothing bias. Indeed, Lindsay et al. (1991) found that using the sequential lineup procedure mitigated the effect clothing bias was having on false identifications. The CCC can account for this: When the pictures were presented all at once (i.e., using the simultaneous procedure) witnesses could use their inferential processing within this 
context to compare the pictures with each other and infer that the lineup member who is dressed in the same clothing must be the perpetrator. In contrast, when the lineup procedure removed this context by presenting the pictures individually (i.e., using the sequential procedure) this reduced witnesses' ability to use a deliberative process to infer on the basis of the clothing bias who the suspect was.

Second, witness are more likely to choose from a lineup when the administrator was not blind compared to when they were blind (Greathouse \& Kovera, 2009; Phillips, McAuliff, Kovera, \& Cutler, 1999). Also, witnesses - especially those with weaker memories - appear to look for indications from the lineup administrator as to the identity of the suspect in the lineup when they are motivated to make an identification (Greathouse \& Kovera, 2009). These results are consistent with the inferential-based framework in that witnesses in the target-present condition will not be strongly affected by the administrators influence because they have a strong ecphoric experience, resulting in less reliance on inferential processing. However, witnesses who view a target-absent lineup should have a relatively weak ecphoric experience and should therefore search for non-memorial information, using an inferential process to aid their decision-making. Thus, according to the CCC the double-blind procedure mitigates the negative effects of administrator influence.

Third, a recent finding showed evidence of a novel postdictor of eyewitness accuracy. Charman and Cahill (2012) reasoned that witnesses who view a target-present lineup will be more likely to have a strong ecphoric experience which tends to be associated with accurate identifications. However, witnesses who view a target-absent lineup will be more likely to have a weak ecphoric experience which tends to be 
associated with inaccurate identifications. As a consequence of the strength of the ecphoric experience, witnesses will differ in their memory of the fillers in the lineup: Witnesses who have a strong ecphoric experience will not need to engage in inferential processing (i.e., they won't spend much time looking at the fillers) whereas witnesses who have a weak ecphoric experience will engage in inferential processing (i.e., they will spend time looking at the fillers). Thus, the extent to which witnesses engage in inferential processing will lead to detectable differences in their memory of the fillers in the lineup, with greater memory for fillers indicative of more inferential processing. Indeed, results indicated witnesses’ memory for fillers significantly postdicted identification accuracy: The more fillers remembered, the more likely the witness was to have made a false identification. These results are consistent with the inferential-based framework and show independent evidence that the level of inferential processing engaged by witnesses is dependent upon their ecphoric experience.

\section{Practical Implications}

These data provide important implications for gathering eyewitness data in the real world. First, data suggest that non-memorial cues provide no benefit to the reliability of eyewitness identifications. Of the non-memorial cues examined in the literature (e.g., clothing bias, administrative influence, co-witness information, lineup bias, etc.), all lead to an increase in false identifications without affecting correct identifications. Indeed, the non-memorial cue in the current studies increased false identifications while simultaneously decreasing correct identifications. This consistent pattern of data shows that the presence of a non-memorial cue is actually counterproductive to the purpose of a lineup. In a real investigation the purpose of a lineup is to provide probative value 
regarding the guilt of the suspect in the lineup (Charman \& Wells, 2007a). This can be accomplished by calculating a diagnosticity ratio, which is the proportion of correct identifications divided by the proportion of false identifications (Wells \& Lindsay, 1980). Therefore, by increasing false identifications without increasing correct identifications (or even decreasing correct identifications, as in Study 2), the presence of non-memorial cues tend to reduce the diagnosticity of lineups (and hence the probative value of an identification). Indeed, the diagnosticity ratio was lower when the non-memorial cue was on the target (2.12) than when there was no non-memorial cue (11.03). As a result police should strive to remove as many non-memorial influences as possible as they offer no benefit. For example, the non-memorial cue used in the present study is essentially cowitness information. In real life there are often multiple witnesses to a crime and therefore it would behoove officers to prevent witnesses from communicating with each other, particularly about their lineup identification decision.

Second, consistent with the CCC, the current data indicate that non-memorial cues have a greater effect when a witness has a weak ecphoric experience. Because a witness’s ecphoric experience is driven by both their memory strength and the match between the lineup members and their memory of the perpetrator, research studies may be showing a greater effect of non-memorial cues on choosing than would be shown among real-world witnesses. For instance, in almost all eyewitness studies, all witnesses, regardless of their reported quality of memory, are shown a lineup and asked to make an identification. In contrast, in real life cases, particularly ones with multiple witnesses, police officers will often only show lineups to witnesses that self-report having had a high quality memory of the perpetrator. All other factors being equal, empirical findings 
of various non-memorial cues will likely reveal a greater effect because real life witnesses who will tend to have a weaker ecphoric experience are never shown a lineup. Thus, the effects we show in the laboratory may in fact be overestimating the impact of non-memorial factors on eyewitness accuracy.

Relatedly, the method used by both researchers and expert witnesses to measure the effect non-memorial cues have on witness choosing behavior - the mock-witness paradigm - may tend to overestimate bias. Mock-witnesses by definition have no memory of the perpetrator; thus, they must use a purely inferential process to make an identification decision. As a result, mock witness paradigms should show a strong effect of non-memorial cues on identification rates, producing large estimates of bias. However, this paradigm may be overestimating the influence any given non-memorial cue is having on witness choosing behavior: Since real world witnesses have a memory of a perpetrator, they should tend to experience some degree of an ecphoric experience when viewing a lineup (particularly a target-present lineup), making them less susceptible to the effect of non-memorial cues.

Third, the framework of the CCC does offer at least one simple safeguard for police officers to help mitigate the effect of non-memorial cues. When constructing a lineup they should ensure that they include a current photograph of the suspect. Again, a witness's ecphoric experience is driven by both their memory strength and the ecphoric match between the lineup members and their memory of the perpetrator. While investigators have no control over the memorial experience of their witnesses they can increase the chances that a witness will have a strong ecphoric experience by using 
current photographs in the lineup; this in turn should make witnesses less susceptible to non-memorial cues in the lineup, thus increasing their accuracy overall.

\section{Limitations}

There are at two important limitations of the present work. First, to examine CCC's prediction of the non-memorial cue on confidence, we had to examine only witnesses who made a suspect identification. But this is a self-selected variable; in other words, we did not force witnesses to choose. As a consequence, because the rates of choosing the suspect differed across cue conditions (i.e., the cue-target condition resulted in more suspect identifications than the no-cue condition), we lose random assignment to condition. As a result, causal conclusions are impossible to draw as to the effect of a competing or corroborating cue on confidence in an identification. Future research could attempt to control for suspect identification. For example, Wells, Bradfield, and Olson (2002) successfully manipulated witness accuracy by (a) forcing all witnesses to choose, and (b) including a highly similar innocent suspect in target-absent lineups. As a consequence, the vast majority of witness identified the target. A similar procedure may be useful in testing the CCC's predictions regarding competing and corroborating cues on witness confidence.

Second, the use of only one type of non-memorial cue limits the generalizability of these data. It is unknown whether the observed patterns of data will occur across the myriad possible non-memorial cues. Indeed, data from Study 1 indicated that only certain non-memorial cues affected choosing behavior. Why did some of the cues affect choosing behavior while others did not? Future research should address this question. One possible explanation is that a non-memorial cue will only affect choosing behavior 
insofar that the inferential process indicates to the witness that the cue possesses diagnostic information. Study 1 provided preliminary support for this explanation. For example, contrast the circle non-memorial cue (which showed an effect on choosing) with the tilted non-memorial cue (which did not show an effect on choosing). It is easier to see that a person might assume that the reason why a lineup member is circled is because someone else believes that is the perpetrator. However, a picture being tilted at an angle in a lineup may be less likely to convey any diagnostic information as to the identity of the suspect. Future research should examine witnesses' attributions for the reasons why cues are present in the lineup, and whether those attributions moderate the effect of cues on choosing behavior.

\section{Future Directions}

The ultimate goal of eyewitness researchers is to develop procedures that help to increase correct identifications and reduce false identifications. It is clear that few procedures within the literature have had much success in increasing hits, whereas the majority of procedures that have been recommended have been beneficial at reducing false identifications. This is likely because it is difficult to develop a procedure that fosters a stronger ecphoric experience because witnesses' ecphoric experience is dependent largely upon their quality of memory, which cannot be controlled by the legal system. However, there may exist ways to increase ecphoric experience. For example, using clear photographs in a lineup that accurately depict the appearance of the perpetrator at the time of the crime and reducing the retention interval between the crime and the lineup task should both help a witness have a relatively strong ecphoric experience if shown a target-present lineup. Thus, future research should investigate 
these and other possible ways to increase the level of ecphoric experience a witness may have.

According to the inferential-based framework, many of the various manipulations in the literature that increase false identifications do so because witnesses engage in inferential processing, particularly when they have a weak ecphoric experience. Thus, procedures and/or instructions that discourage witnesses from engaging in inferential processing would be extremely impactful. Perhaps an additional lineup instruction instructing witnesses to avoid inferential processing could prevent this detrimental deliberative processing, and thus improve the diagnosticity of lineup identifications. This could even be accomplished by modifying the wording of the recommended unbiased instructions. For example, the following instruction may help prevent inferential-based processing: "Please keep in mind that the perpetrator may or may not be present in the lineup. Also, keep in mind your task is to use your memory to make your lineup decision not to use other non-memory based factors". Not only should this instruction reduce the likelihood of false identifications itself, but it should also help mitigate the negative effects of inferential processing.

There are likely multiple factors driving a witness to use inferential processing but one obvious factor is that of motivation. Witnesses who view a lineup are motivated for various reasons (e.g., justice, self-esteem boost, belief in a just world) to make an identification from a lineup. The very nature of the task likely implies to witnesses that the guilty party is in the lineup and therefore it is their job to simply identify the perpetrator. Surprisingly, very little research has investigated the role of motivation in witness choosing behavior. And although some manipulations, such as unbiased 
instructions, are designed to reduce the belief that lineups always contain the actual perpetrator, witnesses still tend to make false identifications even when given those unbiased instructions, suggesting that they are nonetheless motivated to pick someone from the lineup. Thus, future research would be well guided to develop new lineup methods that specifically reduce the role motivation plays in witness choosing behavior. Indeed, it is possible, and consistent with the CCC, that motivation plays a crucial causal role in the effect of non-memorial cues on choosing behavior. Specifically, witnesses who have a weak ecphoric experience may be more likely to engage in inferential processing only if they are motivated to make an identification; thus, motivated witnesses who experience a weak ecphoric experience are the witnesses who will be affected most by non-memorial cues. A witness who has a weak ecphoric experience but is not highly motivated may not engage in inferential processing and may be more likely to (correctly) reject the lineup. Future research should examine whether the effect of non-memorial cues on identification accuracy is moderated by a witness's motivation to make an identification. 


\section{REFERENCES}

Atkinson, R. C., Hertmann, D. J., \& Wescourt, K. T. (1974). Search processes in recognition memory. In R. L. Solso (Ed.), Theories in cognitive psychology: The Loyola symposium (pp. 101-146). Potomac, MD: Erlbaum.

Bradfield, A. L., Wells, G. L., \& Olson, E. A. (2002). The damaging effect of confirming feedback on the relation between eyewitness certainty and identification accuracy. Journal of Applied Psychology, 87, 112-120. doi:10.1037/0021-9010.87.1.112

Brewer, N., Weber, N., \& Semmler, C. (2007). A role for theory in eyewitness identification research. In R. C. L. Lindsay, D. F. Ross, J. D. Read, \& M. Toglia (Eds.), Handbook of eyewitness psychology: Memory for people (Vol. 2, pp. 201218). Mahwah, NJ: Lawrence Erlbaum.

Brewer, N., \& Wells, G. L. (2011). Eyewitness identification. Current Directions in Psychological Science, 20(1), 24-27. doi:http://dx.doi.org/10.1177/0963721410389169

Carlson, C. A., Gronlund, S. D., \& Clark, S. E. (2008). Lineup composition, suspect position, and the sequential lineup advantage. Journal of Experimental Psychology: Applied, 14(2), 118-128. doi:http://dx.doi.org/10.1037/1076898X.14.2.118

Charman, S. D., \& Cahill, B. S. (2012). Witnesses’ memories for lineup fillers postdicts their identification accuracy. Journal of Applied Research in Memory and Cognition, 1(1), 11-17. doi:http://dx.doi.org/10.1016/j.jarmac.2011.08.001

Charman, S., \& Wells, G. L. (2007a). Applied lineup theory Lawrence Erlbaum Associates Publishers, Mahwah, NJ. Retrieved from http://ezproxy.fiu.edu/login?url=http://search.proquest.com/docview/621689 $\underline{051}$ ?accountid=10901

Charman, S. D., \& Wells, G. L. (2007b). Eyewitness lineups: Is the appearance-change instruction a good idea? Law and Human Behavior, 31(1), 3-22. doi:http://dx.doi.org/10.1007/s10979-006-9006-3

Charman, S. D., \& Wells, G. L. (2012). The moderating effect of ecphoric experience on post-identification feedback: A critical test of the cues-based inference conceptualization. Applied Cognitive Psychology, 26(2), 243-250. doi:http://dx.doi.org/10.1002/acp.1815

Clare, J., \& Lewandowsky, S. (2004). Verbalizing facial memory: Criterion effects in verbal overshadowing. Journal of Experimental Psychology: Learning, Memory, and Cognition, 30(4), 739-755. doi:http://dx.doi.org/10.1037/0278-7393.30.4.739 
Clark, S. E. (2003). A memory and decision model for eyewitness identification. Applied Cognitive Psychology, 17(6), 629-654. doi:http://dx.doi.org/10.1002/acp.891

Clark, S. E. (2008). The importance (necessity) of computational modelling for eyewitness identification research. Applied Cognitive Psychology, 22(6), 803-813. doi:http://dx.doi.org/10.1002/acp.1484

Clark, S. E., Marshall, T. E., \& Rosenthal, R. (2009). Lineup administrator influences on eyewitness identification decisions. Journal of Experimental Psychology: Applied, 15(1), 63-75. doi:http://dx.doi.org/10.1037/a0015185

Cohen, J. (1992). A power primer. Psychological Bulletin, 112(1), 155-159. doi:http://dx.doi.org/10.1037/0033-2909.112.1.155

Cutler, B. L., \& Penrod, S. D. (1988). Improving the reliability of eyewitness identification: Lineup construction and presentation. Journal of Applied Psychology, 73(2), 281-290. doi:http://dx.doi.org/10.1037/0021-9010.73.2.281

Cutler, B. L., Penrod, S. D., \& Martens, T. K. (1987). The reliability of eyewitness identification: The role of system and estimator variables. Law and Human Behavior, 11(3), 233-258. doi:http://dx.doi.org/10.1007/BF01044644

Doob, A. N. \& Kirshenbaum, H. (1973). Bias in police lineups-partial remembering. Journal of Police Science and Administration, 1, 287-293.

Dunning, D., \& Perretta, S. (2002). Automaticity and eyewitness accuracy: A 10 - to - 12 second rule for distinguishing accurate from inaccurate positive identifications. Journal of Applied Psychology, 87, 951-962. doi:10.1037/0021-9010.87.5.951

Dunning, D., \& Stern, L. B. (1994). Distinguishing accurate from inaccurate identifications via inquiries about decision processes. Journal of Personality and Social Psychology, 67, 818-835. doi:10.1037/0022-3514.67.5.818

Ebbesen, E. B., \& Flowe, H. D. (2002). Simultaneous v. sequential lineups: What do we really know? Retrieved from http://www2.le.ac.uk/departments/psychology/ppl/hf49/SimSeq\%20Submit . .pdf

Festinger, L. (1954). A theory of social comparison processes. Human Relations, 7, 117140. doi:http://dx.doi.org/10.1177/001872675400700202

Flowe, H. D., \& Humphries, J. E. (2011). An examination of criminal face bias in a random sample of police lineups. Applied Cognitive Psychology, 25(2), 265-273. doi:http://dx.doi.org/10.1002/acp.1673 
Gardiner, J. M., Ramponi, C., \& Richardson-Klavehn, A. (1998). Experiences of remembering, knowing, and guessing. Consciousness and Cognition: An International Journal, 7(1), 1-26. Retrieved from http://ezproxy.fiu.edu/login?url=http://search.proquest.com/docview/619324728? accountid=10901

Godden, D. R., \& Baddeley, A. D. (1975). Context-dependent memory in two natural environments: On land and underwater. British Journal of Psychology, 66(3), 325-331. Retrieved from http://ezproxy.fiu.edu/login?url=http://search.proquest.com/docview/616221682? accountid=10901

Goodsell, C. A., Gronlund, S. D., \& Carlson, C. A. (2010). Exploring the sequential lineup advantage using WITNESS. Law and Human Behavior, 34(6), 445-59. doi:http://dx.doi.org/10.1007/s10979-009-9215-7

Greathouse, S. M., \& Kovera, M. B. (2009). Instruction bias and lineup presentation moderate the effects of administrator knowledge on eyewitness identification. Law and Human Behavior, 33(1), 70-82. doi:http://dx.doi.org/10.1007/s10979008-9136-x

Gronlund, S. D., Wixted, J. T., \& Mickes, L. (2014). Evaluating eyewitness identification procedures using receiver operating characteristic analysis. Current Directions in Psychological Science, 23(1), 3-10. doi:http://dx.doi.org/10.1177/0963721413498891

Haw, R. M., \& Fisher, R. P. (2004). Effects of administrator-witness contact on eyewitness identification accuracy. Journal of Applied Psychology, 89(6), 11061112. doi:http://dx.doi.org/10.1037/0021-9010.89.6.1106

Hayes, A. F. (2013). Introduction to mediation, moderation, and conditional process analysis: A regression-based approach Guilford Press, New York, NY. Retrieved from http://ezproxy.fiu.edu/login?url=http://search.proquest.com/docview/144931159 5?accountid=10901

Jacoby, L. L. (1991). A process dissociation framework: Separating automatic from intentional uses of memory. Journal of Memory and Language, 30(5), 513-541. Retrieved from http://ezproxy.fiu.edu/login?url=http://search.proquest.com/docview/618087 $\underline{829}$ ?accountid=10901

Kelley, C. M., \& Lindsay, S. D. (1993). Remembering mistaken for knowing: Ease of retrieval as a basis for confidence in answers to general knowledge questions. Journal of Memory and Language, 32, 1-24. doi:10.1006/jmla.1993.1001 
Lane, S. M., \& Meissner, C. A. (2008). A 'middle road' approach to bridging the basicapplied divide in eyewitness identification research. Applied Cognitive Psychology, 22(6), 779-787. doi:http://dx.doi.org/10.1002/acp.1482

Leippe, M. R., \& Eisenstadt, D. (2007). Eyewitness confidence and the confidenceaccuracy relationship in memory for people. In R. C. L. Lindsay, D. F. Ross, J. D. Read., \& M. P. Toglia (Eds.), The Handbook of Eyewitness Psychology: Memory for People. Mahwah, NJ: Lawrence Erlbaum Associates.

Lindsay, R. C. L., \& Wells, G. L. (1980). What price justice? exploring the relationship of lineup fairness to identification accuracy. Law and Human Behavior, 4(4), 303313. doi:http://dx.doi.org/10.1007/BF01040622

Lindsay, R. C. L., \& Wells, G. L. (1985). Improving eyewitness identifications from lineups: Simultaneous versus sequential lineup presentation. Journal of Applied Psychology, 70(3), 556-564. doi:http://dx.doi.org/10.1037/0021-9010.70.3.556

Logan, G. D. (1988). Toward an instance theory of automatization. Psychological Review, 95(4), 492-527. doi:http://dx.doi.org/10.1037/0033-295X.95.4.492

Malpass, R. S., \& Devine, P. G. (1981). Eyewitness identification: Lineup instructions and the absence of the offender. Journal of Applied Psychology, 66(4), 482. Retrieved from http://ezproxy.fiu.edu/login?url=http://search.proquest.com/docview/213938260? accountid=10901

McQuiston, D. E., \& Malpass, R. S. (2002). Validity of the mockwitness paradigm: Testing the assumptions. Law and Human Behavior, 26(4), 439-453. doi:http://dx.doi.org/10.1023/A:1016383305868

McQuiston-Surrett, D., Malpass, R. S., \& Tredoux, C. G. (2006). Sequential vs. simultaneous lineups: A review of methods, data, and theory. Psychology, Public Policy, and Law, 12(2), 137-169. doi:http://dx.doi.org/10.1037/10768971.12.2.137

Meissner, C. A., Tredoux, C. G., Parker, J. F., \& MacLin, O. H. (2005). Eyewitness decisions in simultaneous and sequential lineups: A dual-process signal detection theory analysis. Memory \& Cognition, 33(5), 783-792. doi:http://dx.doi.org/10.3758/BF03193074

Memon, A., Gabbert, F., \& Hope, L. (2004). The ageing eyewitness. Forensic psychology: Concepts, debates and practice. (pp. 96-112) Willan Publishing, Devon. Retrieved from http://ezproxy.fiu.edu/login?url=http://search.proquest.com/docview/620338329? accountid=10901 
Munsterberg, H. (1899). Psychology and history. Psychological Review, 6(1), 1-31.

Munsterberg, H. (1908). On the witness stand McClure: New York. Retrieved from http://ezproxy.fiu.edu/login?url=http://search.proquest.com/docview/614870 735?accountid=10901

Palmer, M. A., Brewer, N., McKinnon, A. C., \& Weber, N. (2010). Phenomenological reports diagnose accuracy of eyewitness identification decisions. Acta Psychologica, 133(2), 137-145. doi:http://dx.doi.org/10.1016/j.actpsy.2009.11.002

Phillips, M. R., McAuliff, B. D., Margaret, B. K., \& Cutler, B. L. (1999). Double-blind photoarray administration as a safeguard against investigator bias. Journal of Applied Psychology, 84(6), 940-951. Retrieved from http://ezproxy.fiu.edu/login?url=http://search.proquest.com/docview/213941 $\underline{601}$ ?accountid=10901

Rhead, L. M., Rodriguez, D. N., Korobeynikov, V., Yip, J. H., \& Kovera, M. B. (2015). The effects of lineup administrator influence and mortality salience on witness identification accuracy. Journal of Forensic Psychology Practice, 15(3), 248274. doi:http://dx.doi.org/10.1080/15228932.2015.1041362

Rosenthal, R. (1966). Experimenter effects in behavioral. New York, NY: AppletonCentury Crofts.

Rosenthal, R., \& Rosnow, R. L. (1991). Essentials of behavioral research: Methods and data analysis. New York: McGraw-Hill.

Shaw, J.S., III. (1996). Increases in eyewitness confidence resulting from postevent questioning. Journal of Experimental Psychology: Applied, 2, 126146. doi:10.1037/1076-898X.2.2.126

Smith, S. M. (1988). Environmental context-dependent memory. Memory in context: Context in memory. (pp. 13-34) John Wiley \& Sons, Oxford. Retrieved from http://ezproxy.fiu.edu/login?url=http://search.proquest.com/docview/617497 396? accountid=10901

Smith, S. M., Glenberg, A., \& Bjork, R. A. (1978). Environmental context and human memory. Memory \& Cognition, 6(4), 342-353. Retrieved from http://ezproxy.fiu.edu/login?url=http://search.proquest.com/docview/616356910? accountid=10901

Smith, S. M., Lindsay, R. C. L., \& Pryke, S. (2000). Postdictors of eyewitness errors: Can false identification be diagnosed? Journal of Applied Psychology, 85, 542550. doi:10.1037/0021-9010.85.4.542 
Sporer, S. L. (1992). Post-dicting eyewitness accuracy: Confidence, decision times and person descriptions of choosers and non-choosers. European Journal of Social Psychology, 22, 157-180. doi:10.1002/ejsp.2420220205

Sporer, S. L. (1994). Decision times and eyewitness identification accuracy in simultaneous and sequential lineups. In D.F. Ross, J.D Read, and M.P. Toglia (Eds.) pp. 300-327. Adult eyewitness testimony: Current trends and developments. New York: Cambridge University Press.

Sporer, S., Penrod, S., Read, D., \& Cutler, B. L. (1995). Choosing, confidence, and accuracy: A meta-analysis of the confidence-accuracy relation in eyewitness identification studies. Psychological Bulletin, 118, 315-327. doi:10.1037/00332909.118.3.315

Steblay, N., Dysart, J., Fulero, S., \& Lindsay, R. C. L. (2001). Eyewitness accuracy rates in sequential and simultaneous lineup presentations: A meta-analytic comparison. Law and Human Behavior, 25(5), 459-473. doi:http://dx.doi.org/10.1023/A:1012888715007

Steblay, N. K., Dysart, J. E., \& Wells, G. L. (2011). Seventy-two tests of the sequential lineup superiority effect: A meta-analysis and policy discussion. Psychology, Public Policy, and Law, 17(1), 99-139. doi:http://dx.doi.org/10.1037/a0021650

Steblay, N. K., Wells, G. L., \& Douglass, A. B. (2014). The eyewitness post identification feedback effect 15 years later: Theoretical and policy implications. Psychology, Public Policy, and Law, 20(1), 1-18. doi:http://dx.doi.org/10.1037/law0000001

Tabachnick, B. G., \& Fidell, L. S. (2013). Using multivariate statistics. Boston: Pearson Education.

Tulving, E. (1981). Similarity relations in recognition. Journal of Verbal Learning \& Verbal Behavior, 20(5), 479-496. Retrieved from http://ezproxy.fiu.edu/login?url=http://search.proquest.com/docview/616610019? accountid=10901

Tulving, E. (1982). Synergistic ecphory in recall and recognition. Canadian Journal of Psychology/Revue Canadienne De Psychologie, 36(2), 130-147. doi:http://dx.doi.org/10.1037/h0080641

Tulving, E. (1985). Memory and consciousness. Canadian Psychology/Psychologie Canadienne, 26(1), 1-12. doi:http://dx.doi.org/10.1037/h0080017

Turtle, J., Read, J. D., Lindsay, D. S., \& Brimacombe, C. A. E. (2008). Toward a more informative psychological science of eyewitness evidence. Applied Cognitive Psychology, 22(6), 769-778. doi:http://dx.doi.org/10.1002/acp.1481 
Wells, G. L. (1984). The psychology of lineup identifications. Journal of Applied Social Psychology, 14(2), 89-103. Retrieved from http://ezproxy.fiu.edu/login?url=http://search.proquest.com/docview/616976 172 ? accountid=10901

Wells, G. L., \& Bradfield, A. L. (1998). "Good, you identified the suspect": Feedback to eyewitnesses distorts their reports of the witnessing experience. Journal of Applied Psychology, 83(3), 360-376. doi:http://dx.doi.org/10.1037/00219010.83.3.360

Wells, G. L., \& Luus, C. E. (1990). Police lineups as experiments: Social methodology as a framework for properly conducted lineups. Personality and Social Psychology Bulletin, 16(1), 106-117. Retrieved from http://ezproxy.fiu.edu/login?url=http://search.proquest.com/docview/617752 $\underline{722 \text { ?accountid=10901 }}$

Wells, G. L., Smith, A. M., \& Smalarz, L. (in press). ROC analysis of lineups obscures information that is critical for both theoretical understanding and applied purposes. Journal of Applied Research in Memory and Cognition. doi:10.1016/j.jarmac.2015.08.010

Yonelinas, A. P. (1994). Receiver-operating characteristics in recognition memory: Evidence for a dual-process model. Journal of Experimental Psychology: Learning, Memory, and Cognition, 20(6), 1341-1354. doi:http://dx.doi.org/10.1037/0278-7393.20.6.1341

Yonelinas, A. P. (2001). Consciousness, control, and confidence: The 3 cs of recognition memory. Journal of Experimental Psychology: General, 130(3), 361-379. Retrieved from http://ezproxy.fiu.edu/login?url=http://search.proquest.com/docview/619695440? accountid=10901

Yonelinas, A. P. (2002). The nature of recollection and familiarity: A review of 30 years of research. Journal of Memory and Language, 46(3), 441-517. doi:http://dx.doi.org/10.1006/jmla.2002.2864

Yonelinas, A. P., Kroll, N. E. A., Dobbins, I., Lazzara, M., \& Knight, R. T. (1998). Recollection and familiarity deficits in amnesia: Convergence of remember-know, process dissociation, and receiver operating characteristic data. Neuropsychology, 12(3), 323-339. doi:http://dx.doi.org/10.1037/0894-4105.12.3.323 


\section{Footnote}

${ }^{1}$ This description of a sequential lineup procedure omits several other defining features, for a more complete description of the lineup procedure see Lindsay \& Wells (1985). 
Table 1

Probability and Odds of Identifying the Suspect by Non-memorial Cue and Lineup Type

All Witnesses

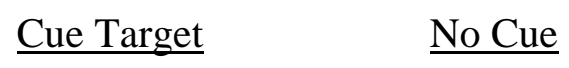

Probability

$\begin{array}{lll}\text { Target Present } & .563^{\mathrm{a}}(n=55) & .761^{\mathrm{b}}(n=67) \\ \text { Target Absent } & .265^{\mathrm{a}}(n=64) & .069^{\mathrm{b}}(n=58)\end{array}$

Odds

$\begin{array}{lcc}\text { Target Present } & 1.292 & 2.722 \\ \text { Target Absent } & 0.3617 & 0.074\end{array}$

\section{Choosers}

$\underline{\text { Cue Target } \quad \text { No Cue }}$

Probability

$\begin{array}{lll}\text { Target Present } & .705^{\mathrm{a}}(n=44) & .817^{\mathrm{a}}(n=60) \\ \text { Target Absent } & .405^{\mathrm{a}}(n=42) & .129^{\mathrm{b}}(n=31)\end{array}$

Odds

$\begin{array}{lll}\text { Target Present } & 2.384 & 4.456 \\ \text { Target Absent } & 0.680 & 0.148\end{array}$

Note. Within each row, probabilities with different superscripts differ at $p \leq .05$ 
Table 2

Probability and Odds of Making an Identification by Non-memorial Cue and Lineup Type

\begin{tabular}{|c|c|}
\hline Cue Target & No Cue \\
\hline
\end{tabular}

Probability

$\begin{array}{lll}\text { Target Present } & .80^{\mathrm{a}}(n=55) & .896^{\mathrm{a}}(n=67) \\ \text { Target Absent } & .656^{\mathrm{a}}(n=64) & .535^{\mathrm{a}}(n=58)\end{array}$

Odds

$\begin{array}{lll}\text { Target Present } & 4.00 & 8.569 \\ \text { Target Absent } & 1.909 & 1.148\end{array}$

Note. Within each row, probabilities with different superscripts differ at $p<.05$ 
Table 3

Probability and Odds of Identifying the Cued Filler by Non-memorial Cue and Lineup Type

Filler 1 Identifications

$\underline{\text { Cue Filler } 1 \quad \underline{\text { No Cue }}}$

Probability

$\begin{array}{lll}\text { Target Present } & .000(n=32) & .045(n=67) \\ \text { Target Absent } & .235(n=34) & .138(n=58)\end{array}$

Odds

$\begin{array}{lll}\text { Target Present } & 0.00 & 0.047\end{array}$

$\begin{array}{ll}\text { Target Absent } \quad 0.308 & 0.16\end{array}$

Filler 6 Identifications

$\underline{\text { Cue Filler } 6} \quad \underline{\text { No Cue }}$

Probability

$\begin{array}{lll}\text { Target Present } & .025(n=40) & .015(n=67) \\ \text { Target Absent } & .192(n=26) & .138(n=58)\end{array}$

Odds

$\begin{array}{lll}\text { Target Present } & 0.026 & 0.015 \\ \text { Target Absent } & 0.238 & 0.16\end{array}$


Table 4

Means (SDs) of Witness Confidence Reports by Non-memorial Cue

\begin{tabular}{ccc}
\hline$\underline{\text { Cue Target }}$ & $\underline{\text { Cue Filler }}$ & $\underline{\text { No Cue }}$ \\
$(n=31)$ & $(n=45)$ & $(n=49)$ \\
$77.90^{\mathrm{a}}(15.96)$ & $67.40^{\mathrm{b}}(16.80)$ & $73.71^{\mathrm{ab}}(17.11)$ \\
\hline
\end{tabular}

Note. Means with different superscripts differ at $p<.05$ 
Table 5

Means (SDs) of Witness Decision Time by Non-memorial Cue and Lineup Type

Combined Cue $\quad$ No Cue

Target Present

20.65 (14.74)
$n=126$
$27.97(19.38)$

$17.22(13.96)$

Target Absent

$$
n=124
$$

$n=57$ 


\begin{tabular}{|l|l|l|}
\hline $\begin{array}{l}\text { Non-Memorial } \\
\text { Cue }\end{array}$ & $b=-0.72$ & $\begin{array}{l}\text { Suspect } \\
\text { Identification }\end{array}$ \\
\cline { 2 - 3 }
\end{tabular}

a) Direct Pathway

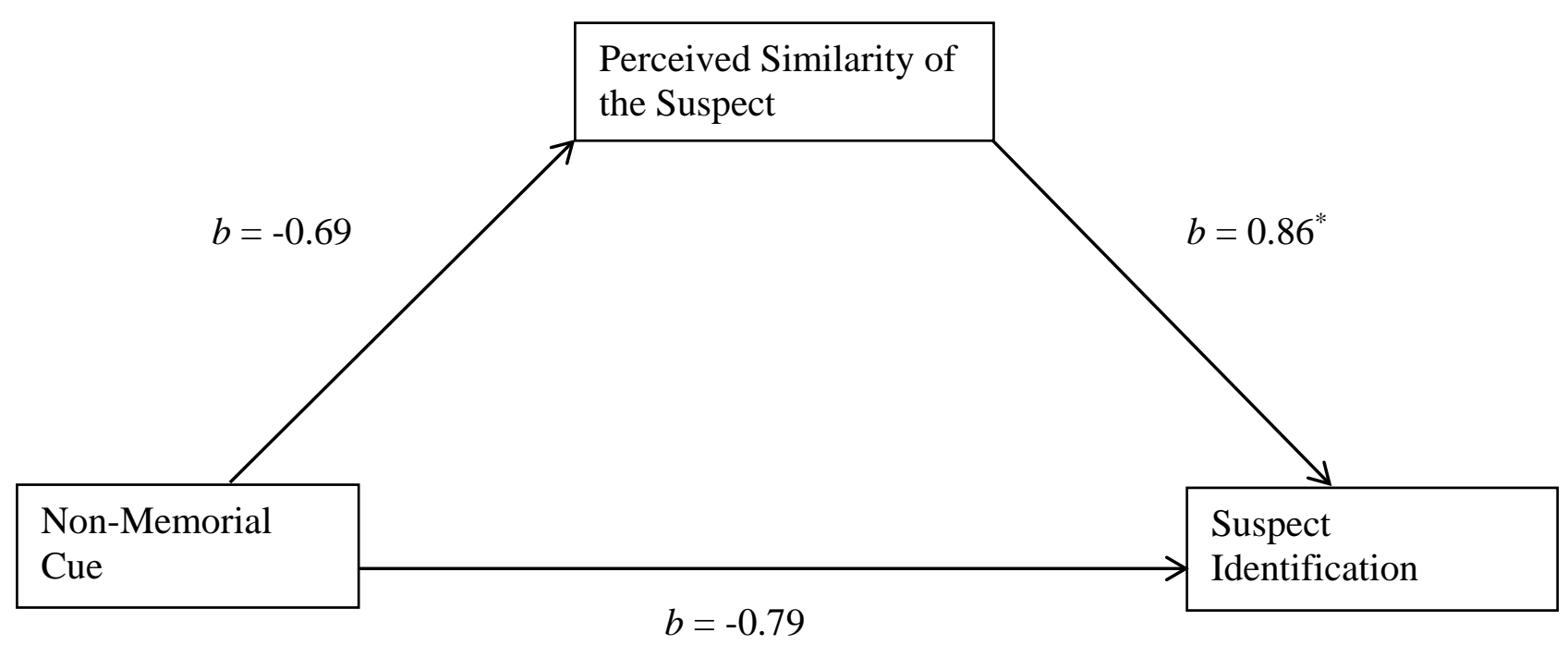

b) Mediated Pathway

Figure 1. Target-present mediation model with predictor variable non-memorial cue (cue-target, no-cue), the mediator variable perceived similarity of the suspect, and the outcome variable suspect identification (yes, no). Panel a represents the total effect of non-memorial cue on suspect identification. Panel b represents the direct and indirect effects of non-memorial cue on suspect identification. ${ }^{*} p<.05$ 


\begin{tabular}{|l|l|l|}
\hline $\begin{array}{l}\text { Non-Memorial } \\
\text { Cue }\end{array}$ & $b=1.59^{* *}$ & $\begin{array}{l}\text { Suspect } \\
\text { Identification }\end{array}$ \\
\cline { 2 - 3 }
\end{tabular}

a) Direct Pathway

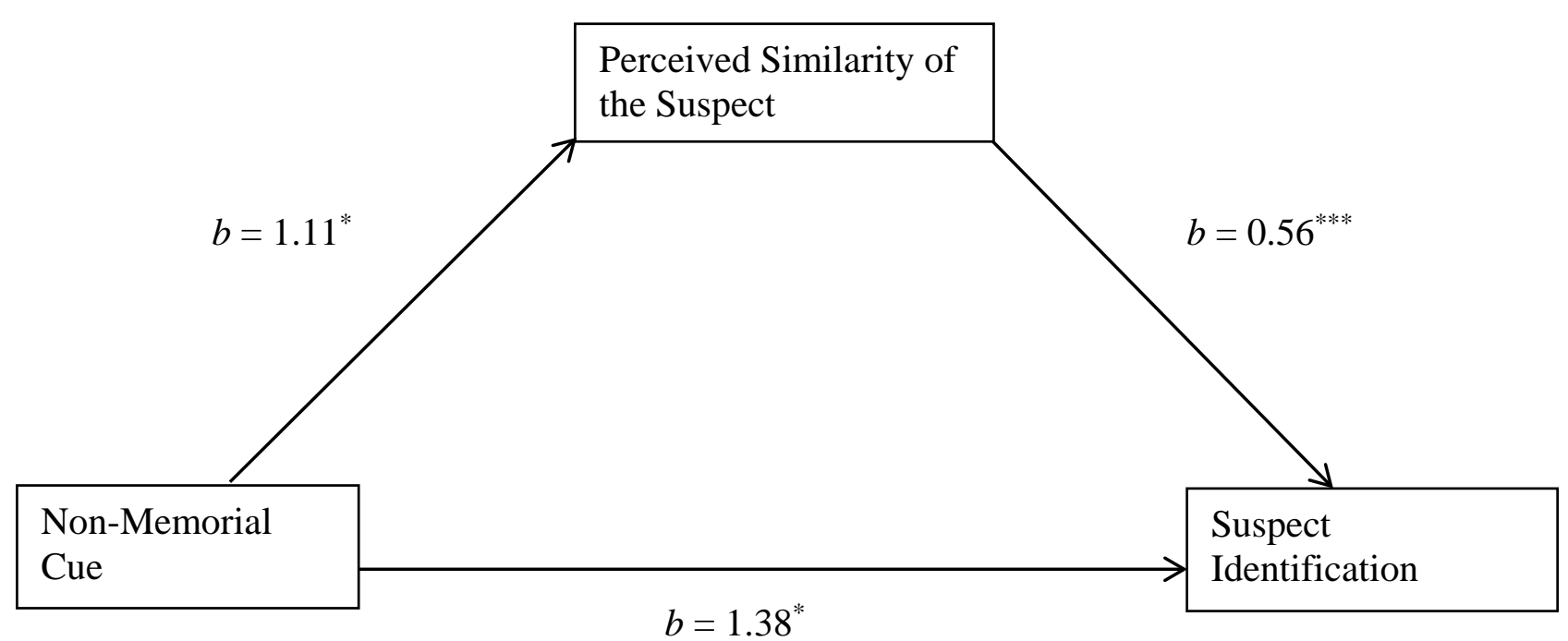

b) Mediated Pathway

Figure 1. Target-absent mediation model with predictor variable non-memorial cue (cue-target, no-cue), the mediator variable perceived similarity of the suspect, and the outcome variable suspect identification (yes, no). Panel a represents the total effect of non-memorial cue on suspect identification. Panel b represents the direct and indirect effects of non-memorial cue on suspect identification. ${ }^{*} p<.05,{ }^{* *} p<.01,{ }^{* * *} p<.001$. 


\section{APPENDIX}

\section{Memory Questionnaire}

\section{RKG Judgments}

Thinking back to your lineup identification decision. Please use the following

descriptions to indicate which option best reflects your experience in making your lineup identification. Please carefully read each description before making your decision.

Remember: If you became consciously aware again of some aspect or aspects of what happened or what was experienced at the time you viewed the video (e.g., aspects of the physical appearance of the individual in the video, or of something that happened in the room, or of what one was thinking or doing at that time). An example of a Remember judgment would be when you recognize someone, and you remember talking to them at the party you attended the previous weekend.

Know: If you recognized the thief from the video but you cannot recollect consciously anything about its actual occurrence or what happened or what was experienced at the time you viewed the video. An example of a Know judgment would be when you are confident you recognize someone, because of strong feelings of familiarity, but you have no recollection of seeing this person before. You cannot remember anything about them. Guess: If your lineup identification was NOT accompanied by a conscious recollection of its prior occurrence when you viewed the video NOR was it accompanied by any feelings of familiarity. That is, your lineup identification was made based on an educated Guess. 


\section{Open-ended Assessments of Decision Processes}

Please describe why you made your lineup decision. That is, why did you choose $\mathrm{X}$ lineup member or why did you choose the "not there option”.

Was there anything about the lineup that lead to your lineup decision other than your memory of the target photo? If so, please explain.

Did one of the photos in the lineup "stand out" from the other photos in the lineup? If so, please explain.

If you noticed that one of the photos in the lineup "stood out" from the other photos in the lineup do you think this influenced your decision? If so, please explain.

Did you notice that one of the photos in the lineup was circled?

If so, do you think this influenced your lineup decision? Please explain. While viewing the lineup did you feel motivated to make an identification? If so, please explain.

Imagine you witnessed a crime and the police ask you to view a lineup to see if you can identify the perpetrator. Before viewing the lineup would you assume the actual perpetrator is in the lineup?

If so, please explain why you think this and how you think this might affect your lineup decision making.

Imagine you witnessed a crime and the police ask you to view a lineup to see if you can identify the perpetrator and while you are looking at the lineup you fail to recognize any of the lineup members. Would you then look for any clues either in the lineup or 
provided by the detective to help you figure out who the perpetrator is? If so, please explain.

\section{Endorsements of Decision Process}

There are a number of different strategies witnesses may use when trying to make a lineup identification. Some of these are listed below. You may have used all, some, or none of these strategies. Please indicate which of the following strategies you used when making your identification decision by placing an ' $\mathrm{X}$ ' beside any of the strategies that you used.

I compared facial features of each of the photos to my memory of the thief

His face just popped out at me

I first eliminated the ones definitely not him

I thought about reasons why the lineup members might be the thief

I just recognized him, I cannot explain why

I compared the photos to each other

I looked for a lineup member that matched my memory of the thief

I had to think to figure out my decision

I picked the person who I reasoned the researchers wanted me to pick

The photos that you saw in the lineup may have had an impact on your decision in various ways. Some of these ways are listed below. Please indicate which of the following statements describes how the photos influenced your decision by placing an ' $\mathrm{X}$ ' beside the statements that describes the photos' influence. (You may indicate all, some, or none of these statements).

They helped me to confirm/reinforce my decision after I made it 
They had little influence on my decision

They confused me; they made the task more difficult

They were all so similar that they made me less confident

Which of the following had a greater impact on your decision?

The photos in the lineup

My memory

\section{Self-reported Viewing Conditions}

How good of a view did you get of the thief?

$\begin{array}{llllllllll}1 & 2 & 3 & 4 & 5 & 6 & 7 & 8 & 9 & 10\end{array}$

Very poor

Very good

When looking at the thief I actively tried to memorize his face.

$\begin{array}{llllllllll}1 & 2 & 3 & 4 & 5 & 6 & 7 & 8 & 9 & 10\end{array}$

Strongly Disagree

Strongly Agree

Throughout the event I paid close attention to the thief's face.
123
34
4
$6 \quad 7$
89
10
Strongly Disagree
Strongly Agree

How clear is the image you have in your memory of the thief you saw in the video?

$\begin{array}{llllllllll}1 & 2 & 3 & 4 & 5 & 6 & 7 & 8 & 9 & 10\end{array}$

Not at all clear

Very clear 
How distinctive was the thief's face?

$\begin{array}{llllllllll}1 & 2 & 3 & 4 & 5 & 6 & 7 & 8 & 9 & 10\end{array}$

Not at all Distinctive

Very Distinctive

Throughout the event I paid close attention to the thief's actions.

$\begin{array}{llllllllll}1 & 2 & 3 & 4 & 5 & 6 & 7 & 8 & 9 & 10\end{array}$

Strongly Disagree

Strongly Agree

How far away was the thief in the video?

$\begin{array}{llllllllll}1 & 2 & 3 & 4 & 5 & 6 & 7 & 8 & 9 & 10\end{array}$

Not far

Very far

During the event I found myself thinking about how the thief reminded me of someone else.

$\begin{array}{llllllllll}1 & 2 & 3 & 4 & 5 & 6 & 7 & 8 & 9 & 10\end{array}$

Strongly Disagree

Strongly Agree

Based on your memory of the thief's face, how confident are you that you could pick the thief out of a crowd of people?

$\begin{array}{llllllllll}1 & 2 & 3 & 4 & 5 & 6 & 7 & 8 & 9 & 10\end{array}$

Not at all Confident

Completely Confident 
The thief's face reminded me of someone I know.

$\begin{array}{llllllllll}1 & 2 & 3 & 4 & 5 & 6 & 7 & 8 & 9 & 10\end{array}$

Strongly Disagree

Strongly Agree

During the event I made judgments about the thief because based on his facial characteristics.

$\begin{array}{llllllllll}1 & 2 & 3 & 4 & 5 & 6 & 7 & 8 & 9 & 10\end{array}$

Strongly Disagree

Strongly Agree

During the crime I found it difficult to pay attention to details.

$\begin{array}{llllllllll}1 & 2 & 3 & 4 & 5 & 6 & 7 & 8 & 9 & 10\end{array}$

Strongly Disagree

Strongly Agree

Generally, how good is your recognition memory for the faces of strangers?

$\begin{array}{rrrrrrrrrr}1 & 2 & 3 & 4 & 5 & 6 & 7 & 8 & 9 & 10 \\ & \\ & & & & & & & & & \end{array}$

How well were you able to make out specific features of the thief's face from the video?

$\begin{array}{llllllllll}1 & 2 & 3 & 4 & 5 & 6 & 7 & 8 & 9 & 10\end{array}$

Not at all

Very well 
For how long would you estimate thief's face was in view?

$\begin{array}{llllllllll}1 & 2 & 3 & 4 & 5 & 6 & 7 & 8 & 9 & 10\end{array}$

Very little time

Quite a bit of time

I did not get a clear view of the thief's face.

$\begin{array}{llllllllll}1 & 2 & 3 & 4 & 5 & 6 & 7 & 8 & 9 & 10\end{array}$

Strongly Disagree

Strongly Agree

During the event I found myself trying to understand why the thief was committing the crime.

$\begin{array}{llllllllll}1 & 2 & 3 & 4 & 5 & 6 & 7 & 8 & 9 & 10\end{array}$

Strongly Disagree

Strongly Agree

To what extent do you feel that you have a good basis (enough information) to recognize the thief from a photograph?

$\begin{array}{llllllllll}1 & 2 & 3 & 4 & 5 & 6 & 7 & 8 & 9 & 10\end{array}$

No basis at all

A very good basis

I am much better at remembering faces than I am at remembering names.

$\begin{array}{llllllllll}1 & 2 & 3 & 4 & 5 & 6 & 7 & 8 & 9 & 10\end{array}$

Strongly Disagree

Strongly Agree 
Throughout the event I found myself getting distracted.

$\begin{array}{llllllllll}1 & 2 & 3 & 4 & 5 & 6 & 7 & 8 & 9 & 10\end{array}$

Strongly Disagree

Strongly Agree 


\section{VITA}

\section{BRIAN S. CAHILL}

2005

B.S., Psychology

Illinois State University

Normal, Illinois

2008

M.A., Experimental Psychology

University of Colorado at Colorado Springs

Colorado Springs, Colorado

2015

Ph.D., Legal Psychology

Florida International University

Miami, Florida

\section{PUBLICATIONS AND PRESENTATIONS}

Cahill, B. S., \& Coolidge, F. L. (2007, April). Adult ADHD and personality disorders: Differential comorbidity among its subtypes. Paper presented at the meeting of the Rocky Mountain Psychological Association, Denver, CO.

Cahill, B. S., Charman, S. D. (2011, March). On the nature of deliberative judgments in eyewitness lineup identification tasks. Paper presented at the meeting of the American Psychological Law Society, Miami, Fl.

Cahill, B. S., Coolidge, F. L., \& Segal, D. L. (2006, April). Prevalence of ADHD and its comorbidity in 3,090 prison inmates. Paper presented at the meeting of the Rocky Mountain Psychological Association, Park City, UT

Cahill, B. S., Coolidge, F. L., \& Segal, D. L. (2006, August). The psychometrics of an adult $A D H D$ scale in 3,090 prison inmates. Paper presented at the meeting of the American Psychological Association, New Orleans, LA

Cahill, B. S., Coolidge, F. L., \& Segal, D. L. (2007, August). ADHD: Prevalence and comorbidity in adult prison inmates. Paper presented at the meeting of the American Psychological Association, San Francisco, CA.

Cahill, B. S., Coolidge, F. L., Segal, D. L., \& Klebe, K. J. (2008, August). Psychometrics of the Coolidge Correctional Inventory in 3,962 Prison Inmates. Paper presented at the meeting of the American Psychological Association, Boston, MA.

Cahill, B. S., Coolidge, F. L., Segal, D. L., Klebe, K. J., Marle, P. D., \& Overmann, K. A. (2012). Prevalence of ADHD, its subtypes, and comorbidity subtype differences in adult prison inmates. Behavioral Sciences \& the Law, 30, 154-166. 
Cahill, B. S., Fisher, R. P., \& Rivard, J. J. (2011, March). Catching liars with cartoons. Paper presented at the meeting of the American Psychological Law Society, Miami, Fl.

Cahill, B. S., Greene, E., Yochim, B. P., \& Winter, R. J. (2009, March). The effects of neuroscientific and neuropsychological expert testimony during the sentencing phase of a capital case. Paper presented at the meeting of the American Psychological Law Society, San Antonio, TX.

Charman, S. D. \& Cahill, B. S. (2011, March). On the nature of automatic processes in eyewitness lineup identification tasks. Paper presented at the meeting of the American Psychological Law Society, Miami, Fl.

Charman, S. D. \& Cahill, B. S. (2012). Witnesses' memories for lineup fillers postdicts their identification accuracy. Journal of Applied Research in Memory and Cognition, 1, 11-17.

Charman, S. D., Cahill, B. S., Leins, D., \& Carol, R. (2010, March). Investigating the ability of innocent suspects to generate accurate alibis. Paper presented at the meeting of the American Psychological Law Society, Vancouver, Canada.

Coolidge, F. L., \& Cahill, B. S. (2007, August). Preliminary psychometric characteristics of a child psychopathology brief-screening inventory. Paper presented at the meeting of the American Psychological Association, San Francisco, CA.

Coolidge, F. L., Cahill, B. S., Segal, D. L., Yochim, B. P., Durham, R. L., \& Coolidge, C. M. (2007, August). Nightmares in children: Prevalence, heritability, and comorbid psychopathology. Paper presented at the meeting of the American Psychological Association, San Francisco, CA.

Coolidge, F. L., Segal, D. L., Cahill, B. S., \& Archuleta, J. L. (2008). A new five factor model of psychopathology: Preliminary psychometric characteristics of the Five-Dimensional Personality Test (5DPT). Personality and Individual Differences, 44, 1326-1334.

Coolidge, F. L., Segal, D. L., Cahill, B. S., \& Simenson, J. T. (2010). Psychometric properties of a brief inventory for the screening of personality disorders: The SCATI. Psychology and Psychotherapy: Theory, Research and Practice, 83(4), 395-405.

Coolidge, F. L., Segal, D. L., Klebe, K. J., Cahill, B. S., \& Whitcomb, J. M. (2009). Psychometric properties of the Coolidge Correctional Inventory (CCI) in a sample of 3,962 prison inmates. Behavioral Sciences \& the Law, 27, 713-726.

Coolidge, F. L., Starkey, M. S., \& Cahill, B. S. (2007). A comparison of a parent-rated DSM-IV measure of attention-deficit/hyperactivity disorder and quantitative electroencephalograph parameters in an outpatient sample of children. Journal of Clinical Neurophysiology, 24, 348-351. 